\title{
ON REFRIGERATING AND ICE-MAKING MACHINERY AND APPLIANCES.
}

By Mr. T. B. IIGHTFOOT, of LoNnON.

The subject of Refrigerating and Ice-making Machinery has not hitherto, so far as the author is aware, been dealt with in a comprehensive manner by any engineering society. The purpose therefore of the present paper is to describe the various systems at present in use, giving also short sketches of their development, together with some consiảerations respecting their practical application and working: in the hope that this may prove an acceptable contribution to the Proceedings of the Institution, and lead to a profitable discussion upon a subject, the importance of which is daily becoming more manifest.

The primary function of all refrigerating and ice-making apparatus is to abstract heat, the temperature of the refrigerating agent being of necessity below that of the substance to be cooled. It is obvious however that, without provision either for rejection of the heat thus abstracted, or for renewal of the refrigerating agent, equalisation of temperature would ultimately ensue, and the cooling action would cease. In practice, if the machine is to work continuously, one or other of these means must be adopted; and a complete refrigerating machine therefore consists of an apparatus by which heat is abstracted, in combination either with some system for renewing the heat-absorbing agent, or, as is more usually the case, with a contrivance whereby the abstracted heat is rejected, and the agent is restored to a condition in which it can again be employed for_cooling purposes. 
The subject can be conveniently dealt with under the four following heads :-

1. Apparatus for abstracting heat by the rapid melting of a solid.

2. Machinery and apparatus for abstracting heat by the evaporation of a more or less volatile liquid.

3. Machinery by which a gas is compressed, partially cooled while under compression, and further cooled by subsequent expansion in the performance of work: the cooled gas being afterwards used for abstracting heat.

4. Considerations as to the applications of the various systems.

\section{Apparatus for Abstracting Heat} by the rapid Melting of a Solid.

This is probably the oldest method of artificial cooling. When a substance changes its physical state, and passes from the solid to the liquid form, the force of cohesion is overcome by the addition of energy in the form of heat. The effect may be produced without. change in sensible temperature, if the heat be absorbed at the same rate as it is supplied from without. Thus, as is well known, the temperature of melting ice remains constant at $32^{\circ} \mathrm{Fahr}$; and any increase or decrease in the heat supplied merely hastens or retards the rate of melting, without affecting the temperature. Mixtures of certain salts with water or acids, and of some salts with ice, which form liquids whose freezing points are below the original temperatures of the mixtures, do not however behave in this way; for under ordinary circumstances the tendency to pass into the liquid form is so strong, that heat is absorbed at a greater rate than it can be supplied from without. The store of heat of the melting substances themselves is therefore drawn upon, and the temperature consequently falls. until a balance is set up between the rate of melting and the rate at which heat is supplied from outside. This is what takes place with ordinary freezing mixtures. The amount of the depression in temperature appears to depend to some extent on the state of hydration of the salt, and the percentage of it in the mixture. Almost the only salts used are those of certain alkalies, few others 
possessing the requisite solubility at low temperatures. A list of freezing mixtures usually employed is given in the appended Table 1, pages 239-240.

Such a method of abstracting heat is extremely convenient for the laboratory, and for some other special purposes. Attempts have also been made to apply it commercially on a large scale for the manufacture of ice and for cooling. The late Sir William Siemens. constructed an ice-making apparatus in which calcium chloride was. employed. The reduction in temperature produced by dissolving this salt in water is about $30^{\circ} \mathrm{Fahr}$; 年 but as this was not sufficient for freezing when the initial temperature of the water was about $60^{\circ}$ or $65^{\circ} \mathrm{Fahr}$., a heat interchanger was introduced, by means of which the spent liquor at about $30^{\circ}$ was utilised for cooling the water before it was mixed with the salt; and to the extent of this cooling the degree of cold produced was intensified. The salt was recovered by evaporation, and used over again. Although this apparatus worked well and produced ice, the inventor himself considered the process inferior to mechanical methods, and abandoned it.

In the Toselli machine a mixture of ammonium nitrate and water is used, by means of which a reduction in temperature of about $40^{\circ} \mathrm{Fahr}$. is obtained. The apparatus consists of a vessel in which the solution of the salt is effected, and an ice-can containing several slightly tapering moulds of circular cross-section and of varying sizes. The moulds being filled with water are introduced into the freezing mixture; and in a fow minutes ice is formed round the edges to the thickness of nearly an eighth of an inch. The rings or tubes of ice are then removed and placed one within the other, so forming a small stick of ice.

Ammonium nitrate is also employed in a machine recently brought out in the United States for the production of ice on a large scale. In one form of this apparatus, intended chiefly for domestic purposes, a series of annular vessels, one within the other, is used: the moulds in which the ice is to be formed being placed in the centre. The reduction of temperature produced by the freezing mixture in the outermost vessel cools the water in the second; and this, on salt being added, cools the third; and so on. In this way the cold is 
very much intensified at the centre, and a low temperature can be produced independent of the initial temperature of the water. The number of rings employed varies according to the effect to be produced and the conditions under which the apparatus is applied. The annular vessels together with the ice moulds are carried in a wood casing supported on bearings, the only motive power required being that necessary to rotate the vessels slowly, so as to promote the solution of the salt.

Another form of apparatus, designed for continuous use on a large scale, consists of a vessel into which ammonium nitrate is automatically fed, and in which it enters into solution with water previously cooled in an interchanger by the spent liquor, after the latter has left the ice-making tanks or cooling rooms. The cold brine thus produced is circulated by a pump through the ice tanks, or through pipes placed in the rooms it is desired to cool; and is returned through the interchanger to an evaporating tank, where by means of heat the water is driven off and the salt recovered. This is practically Sir William Siemens' apparatus in a somewhat extended form. The cost of producing 15 tons of ice per 24 hours with such an apparatus of suitable capacity is stated at $7 \mathrm{~s}$. per ton, with good coals at 15s. a ton, and exclusive of depreciation and repairs. This however is probably much too low an estimate, being based upon the erroneous assumption that $1 \mathrm{lb}$. of coal is capable of evaporating $20 \mathrm{lbs}$. of water. Nearly the whole of the coal is used for evaporating the water in recovering the salt, the quantity being given at $2 \frac{1}{2}$ tons of coal for every 15 tons of ice. If however this has been calculated on an evaporntive duty of 20 lbs. of water per lb. of coal, the amount actually used will probably be about 5 tons of coal, which would make the cost per ton of ice $9 s$. 3d. instead of $7 s$. On the other hand it must be remembered that under certain climatic conditions much of the water could be evaporated in the open air, without the use of fuel; in which case the coal consumption, and therefore the cost of ice production, would be greatly lessened. 


\section{Machinery and Apparatug for Abstracting Hrat} by the Evaporation of a more or less Volatile Liquid.

When a liquid changes its physical condition and assumes the state of vapour, heat is absorbed in increasing the energy of the molecules. This heat is absorbed without change in sensible temperature; and the amount thus disposed of is usually called the latent heat of vaporisation. For different liquids different quantities of heat are required; and for the same liquid the amount varies somewhat according to the pressure at which vaporisation oceurs. Other things being equal, the liquid with the highest latent heat will be the best refrigerant, because for a given abstraction of heat the least weight of liquid will be required, and therefore the power expended in working the machine will be the least. The principal systems in which the evaporation of liquids is employed may be treated under the following subdivisions:-

A. Apparatus in which the refrigerating agent is rejected along with the heat it has acquired.

$B$. Machines in which heat only is rejected, the refrigerating agent being restored to its original physical condition by means of mechanical compression and by cooling when under compression.

C. Apparatus in which heat only is rejected, by allowing the refrigerating agent to change its physical condition by entering into solution with a liquid, from which it is afterwards separated by evaporation and recovered.

D. Machinery and apparatus in which heat only is rejected, by changing the physical state of the refrigerating agent by a combination of both mechanical compression and solution, with cooling.

System A.-This is generally known as the vacuum process; for as the refrigerating agent itself is rejected, the only agent of a sufficiently inexpensive character to be employed is water, and this, owing to its high boiling point, requires the maintenance of a high degree of vacuum in order to produce ebullition at the proper 
temperature. In Fig. 1, Plate 52, are shown graphically the vapour tensions of water at temperatures up to boiling point at atmospheric pressure (the actual figures being given in the appended Table 2, page 241); from which it will be seen that at $32^{\circ} \mathrm{Fahr}$. the tension is only $0.089 \mathrm{lb}$. per square inch. In ice-making therefore a degree of vacuum must be maintained at least as high as this.

The earliest machine of this kind appears to have been made in 1755 by Dr. Cullen, who produced the vacuum by means of an airpump. In 1810 Leslie, combining with the air-pump a vessel containing strong sulphuric acid, for absorbing the vapour from the air drawn over and so assisting the pump, succeeded in producing an apparatus by means of which 1 to $1 \frac{1}{2}$ lbs. of ice could be made in a single operation. Vallance and Kingsford followed later, but without practical results; and Carré many years afterwards embodied the same principle in a machine for cooling and for making small quantities of ice, chiefly for domestic purposes. His machine, which is still sometimes used, consists of a small vertical vacuum-pump worked by hand, either by a lever or by a crank, which exhausts the air from the carafe or decanter containing the water or liquid to be frozen or cooled. Between the pump and the water vessel is a lead cylinder, three-quarters full of sulphuric acid, over which the air, and with it the vapour given off from the liquid, is cansed to pass on its way to the pump. The vacuum thus produced causes a rapid evaporation, which quickly lowers the temperature cf the water; and; if the action is prolonged for about four or five minutes, the water becomes frozen into a block of porous opaque ice. The charge of acid is about $4 \frac{1}{2}$ pints, and it is said that from 50 to 60 carafes of about a pint each can be frozen with one charge. So long as the joints are all tight, and the pump is in good order, this apparatus works well; but in practice it has been found troublesome and unreliable, and consequently has never come into anything like general use.

In 1878 Franz Windhausen of Berlin patented a compound vacuum-pump for producing ice direct from water, on a large scale, without the employment of sulphuric acid; and also an arrangement in which sulphuric acid could be used, the acid being cooled by water 
during its absorption of the vapour, and afterwards concentrated, so that a fresh supply was rendered unnecessary. This apparatus was improved on in 1880 ; and in 1881 a machine nominally capable of producing from 12 to 15 tons of ice per 24 hours was put to work experimentally at the Aylesbury Dairy at Bayswater, being afterwards removed to Lillie Road, where it now is. The installation was fully described and illustrated by Carl Pieper in a paper read before the Society of Engineers in November 1882, and by Dr. John Hopkinson at the Society of Arts about the same time.* It consists of six slightly tapered ice-forming vessels of cast iron, of circular cross-section, closed at their bottom ends by hinged doors with air-tight joints, into which water is allowed to flow at a regular rate through suitable nozzles, the cylinders being steam-jacketed in order to allow the ice to be readily discharged. The upper parts of these vessels communicate with the pump through a long horizontal iron vessel of circular section containing sulphuric acid, which, when the machine is in operation, is kept in continual agitation by means of revolving arms. The acid vessel is surrounded with cold water, which carries off most of the heat liberated during the absorption of the vapour. The pump has two cylinders, one double-acting of large size, and a smaller single-acting one. The capacities of these cylinders per revolution are as 62 to 1 . The air and whatever vapour has passed the acid are drawn into the largo pump, which partially compresses and delivers them into a condenser. Here part of the vapour is condensed by the action of cold water, the remainder passing along with the air to the second pump, where they are compressed up to atmospheric tension and discharged. The advantage gained by the use of a compound pump is due to the action of the intermediate condenser, and to the compression being performed in two stages, by which the losses from the clearance spaces in the large pump are rendered much less than they would be if compression to atmospheric pressure were accomplished in a single operation. The effect of the pump is said to be such that a vacuum of half a millimetre of mercury or about $0.0097 \mathrm{lb}$. per square inch can be

* Transactions of the Society of Engineers, 1882, page 145; Journal of the Society of Arte, 1882, vol. 31, page 20. 
continuously maintained : though in actual work about $2 \frac{1}{2}$ millimetres or $0.0484 \mathrm{lb}$. per square inch is as low as is necessary. The concentration of the acid is effected in a lead-lined vessel, in which is a coil of lead piping heated by steam, the pressure in the vessel being kept down by means of an ordinary air-pump. No acid pump is needed, as the transfer from one vessel to another is effected by the pressure of the atmosphere. The comparatively cool weak acid on its way to the concentrator is heated in an interchanger by the strong acid returning from the concentrator. Six blocks of ice, each weighing about $560 \mathrm{lbs}$, are formed in about sixty minutes after starting. The charge of acid is said to serve for four makings of ice, after which it becomes too weak and requires to be concentrated.

The water being admitted into the ice-forming vessels in fine streams offers a large surface for evaporation, and is almost immediately converted into small globules of ice, which fall to the bottom and become cemented together by the freezing of a certain quantity of water that collects there. This water being in a violent state of ebullition, the ice so formed is not solid, but contains spaces or blow-holes, which, as soon as the block is discharged from the vessel, become filled with air and cause opacity. Several attempts have been made to produce transparent ice by the direct vacuum process, but so far without success. Distilled water or water deprived of air has been tried, and hydraulic pressure has been used for compressing the porous opaque blocks; but neither plan has been found practicable commercially. It would appear indeed that the only way to make clear ice by the vacuum process is by forming it in moulds or cells, subjected externally to the action of brine previously cooled by the evaporation of a portion of its water. The cost in this case would necessarily be greater; but the ice would be solid and transparent, and would consequently have a higher commercial value.

The latent heat of liquefaction of water being $142 \cdot 6$, the total heat to be abstracted in order to produce 1 ton of ice from 1 ton of water at $60^{\circ} \mathrm{Fahr}$. is 382,144 units. Taking the latent heat of vaporisation of water at $32^{\circ} \mathrm{Fahr}$. to be $1091 \cdot 7$, it is obvious that $350 \mathrm{lbs}$. must be evaporated to make the ton of ice. But in 
addition the sensible heat of the evaporated water, which entering at $60^{\circ}$ would leave at about $32^{\circ}$, would have to be taken off; and this would require the evaporation of about $9 \frac{1}{4} 1 \mathrm{bs}$. more, making a total of about 360 lbs., without allowance for loss by heat entering from without, which would be considerable. The total water actually used is given by Mr. Pieper at from 10 to 12 tons per ton of ice, including the quantity required for cooling purposes. The fuel consumption is stated to be $180 \mathrm{lbs}$. of coal per ton of ice; but the author understands a much larger quantity is actually required. It is consumed in generating steam for driving the vacuum pump and the concentrator air-pump, and for evaporating the water absorbed by the acid. According to Dr. Hopkinson, the cost of making 1 ton of opaque ice is $4 s$.; but the author believes experience has shown that a much higher figure is required to cover the necessary expenses for repairs and maintenance, which in some parts of the apparatus are very heavy. Windhausen's machine has not met with any extended application in this country, owing no doubt to the opaque and porous condition of the ice produced by it, and to the large and cumbrous nature of the plant, which must doubtless require great care and supervision in working.

In 1878 James Harrison patented a vacuum apparatus for refrigerating liquids by their own partial evaporation, and for making ice. Its chief feature is the revolving cylinder or pump, shown in section in Fig. 3, Plate 53, which affords a simple and efficient means of exhausting large volumes of vapour of low tension, without incurring the loss from friction of ordinary piston-packings, and the trouble of keeping them tight and in good working order, while at the same time the first cost is much reduced. The pump consists of a hollow iron cylinder, revolving on a horizontal axis, and divided into compartments by longitudinal partitions of $L$ section. It is partially filled with a non-evaporable liquid, or one which evaporates only at a temperature considerably in excess of that at which the refrigerating liquid is evaporated, and which is also chemically neutral to the vapour that is brought in contact with it. In practice oil is the liquid used. The refrigerating or ice-making vessels, of any convenient form, are connected by a pipe with one end of a fixed 
hollow axle on which the cylinder revolves; and inside the cylinder another pipe rises up above the level of the liquid, the longitudinal partitions being stopped short at one end to enable this to be done. The compartments move round mouth downwards, earrying with them the vapour with which they are charged, and compressing it to an extent measured by the distance they dip below the surface of the liquid; until, when the lowest position is approached, the compressed vapour is liberated, and rises into a fixed hood near the centre, in communication with a second hollow axle at the opposite end of the cylinder to that at which the vapour enters. Through this second axle the compressed vapour passes to a surface evaporative condenser, in which it is partly condensed by the combined action of direct cooling and of the partial evaporation of water trickling over the surface: the water of condensation together with any air being then compressed to the tension of the atmosphere by a small pump, and discharged. By this process the author is informed it is expected to produce opaque ice on a large scale at a cost of about 18. per ton. The fuel consumption will certainly be very small, because friction, which is a large item in the Windhausen apparatus, is here to a large extent eliminated. There would also be a saving of all the fuel used in concentrating the acid, and of much of the water required for cooling purposes, besides a reduction in the first cost of the plant and in the expense of maintenance.

System B.-This is known as the compression process, and is used with liquids whose vapours condense under pressure at ordinary temperatures. Although prior to 1834 several suggestions had been made with regard to the production of ice and the cooling of liquids by the evaporation of a more volatile liquid than water, the author believes that the first machine really constructed and put to work was made by John Hague in that year, from the designs of Jacob Perkins. According to Sir Frederick Bramwell * the liquid used was one arising from the destructive distillation of caoutchouc. The machine, which so far as the author is aware was never put to work

* Journal of the Society of Arts, 1882, vol. 31, page 77. 
outside of the factory where it was constructed, is shown in section in Fig. 4, Plate 53. The water to be frozen was placed in the jacketed copper pan A, the jacket being partially filled with the volatile liquid, and carefully protected on the outside with a covering of nonconducting material. A pump $\mathrm{P}$ drew off the vapour from the jacket, and delivered it compressed into a worm W, around which cooling water was circulated, the pressure being such as to cause liquefaction. The liquid collected at the bottom of the worm, and returned to the jacket through the pipe $D$, to be again evaporated. This apparatus, though in some respects crude, is yet the parent of all compression machines used at the present time, the only improvements made since the year 1834 having been in matters of constructive detail.

The next advance was made in 1856 and 1857 by James Harrison, who brought out a machine embodying the same principles as that of Perkins, but worked out on a larger and more practical scale. This machine was constructed for the inventor by the late Mr. Siebe, and was the first ice-making apparatus that really came into practical use in this country and was employed for commercial purposes. An improved apparatus of this kind, in which sulphuric ether is used as the refrigerating agent, is still manufactured by Messrs. Siebe Gorman and Co. The vapour tensions of sulphuric ether are shown graphically in Fig. 1, Plate 52, and are also given in the appended Table 2. It is a not very volatile liquid, of specific gravity $0 \cdot 720$, having a latent heat of vaporisation of 165 , and a specific gravity of vapour of $2 \cdot 24$ compared with air. Its boiling point at atmospheric pressure is $96^{\circ}$ Fahr. Messrs. Siebe Gorman and Co.'s machine, applied to the manufacture of clear ice, is shown in elevation and plan in Figs. 6 and 7, Plate 54. It consists of a refrigerator $R$, a water-jacketed pump $P$, driven by the surface-condensing steam-engine $\mathrm{E}$, an ether condenser $\mathrm{D}$, and ice-making tanks $T$ containing copper moulds, around which brine cooled to a low temperature in the refrigerator is circulated by the pump C. The refrigerator $\mathbf{R}$ is a cylindrical vessel of sheet copper, containing clusters of horizontal solid-drawn copper tubes, throngh which the brine successively circulates. The shell is connected with the pump $\mathbf{P}$ by a pipe, the liquid ether from the condenser being 
admitted through a small pipe having a cock $\mathrm{K}$, which is so adjusted as to pass the precise weight of ether that the pump $\mathbf{P}$ will draw off. What this weight is depends entirely on the pressure at which evaporation occurs; the greater the density of the vapour, the greater being the weight drawn off at each revolution of the pump. The pressure at which evaporation occurs is defined by the temperature to which it is desired to reduce the brine, the boiling point of the ether being regulated so as to give the required reduction of temperature and no more; otherwise the apparatus would not work up to its full capacity. The condenser D consists of a cluster of solid-drawn copper tubes, placed horizontally in a wood tank, through which cooling water is circulated, the amount of water required in this country being about 150 gallons per hour for every ton of ice made per twenty-four hours. With the temperature of cooling water available here, liquefaction generally occurs at a pressure of about 3 lbs. per square inch above the atmosphere; but in a warm climate the pressure needed may reach as much as 10 or even $12 \mathrm{lbs}$.

In the apparatus illustrated in Figs. 6 and 7, Plate 54, the ice is made in cans or moulds, as shown in section in Fig. 8. The moulds M, of sheet copper or steel, are filled with the water to be frozen, and are suspended in a tank, through which is kept up a circulation of cold brine from the refrigerator. As soon as the ice I is formed, the moulds are removed and dipped for a few minutes in warm water to loosen the ice, which is then turned out. The sizes of the moulds vary a good deal, according to the capacity of the machine, and the purpose for which the ice is to be used. A common plan is to commence with a thickness of 3 inches for a production of 1 ton per twenty-four hours, and to go up to 9 inches for 10 tons and upwards. The thickness exercises an important bearing upon the number of moulds to be employed for any given output; for, while a 3-inch block can be frozen in eight hours, one 9 inches thick will take about thirty-six hours. The time however varies also according to the temperature at which the brine is worked. For an ether machine, such as that just described, the brine temperature may be taken at from $10^{\circ}$ to $15^{\circ} \mathrm{Fahr}$. 
Another method is that known as the cell system, which is shown in section in Fig. 9, Plate 54. This consists of series of cellular walls W of wrought or cast iron, placed from 12 to 16 inches apart, the space between each pair of walls being filled with the water to be frozen. The cooled brine circulates through the cells, the ice I gradually forming outside, and increasing in thickness until the two opposite layers meet and join together. If thinner blocks are required, freezing may be stopped at any time, and the ice removed. In order to detach the ice from the walls, it may either be left for a time after the circulation of the brine has been stopped, or a better and quicker plan is to pass some warmer brine through the cells.

In order to produce transparent ice, it is necessary that the water should be agitated during freezing, so as to allow the escape of the air set free. When moulds are used, Fig. 8 , this is generally done by means of arms having a vertical or horizontal movement, which are either pushed up by the ice as it forms, leaving the block solid, or work backwards and forwards in the centre of the mould, dividing the block vertically into two equal pieces. With cells, Fig. 9, agitation is generally effected from the bottom by means of paddles. The ice which forms first on the sides of the moulds or cells is generally transparent enough even without agitation. The opacity gradually increases towards the centre, where the two layers meet and join together; agitation is therefore more necessary towards the end of the freezing process than at the beginning. As the quantity of air held in solution by water decreases as its temperature is raised, it is obvious that less agitation will be required in hot than in temperate. climates; for this reason in India and elsewhere agitation is frequently dispensed with altogether.

Machines using ether as the refrigerating medium are also largely made by Messrs. Siddeley and Co. of Liverpool, and Messrs. West and Co. of Southwark; but they present no special features which are not embodied in the apparatus already described, the points of difference being in details to which it is not necessary to refer.

As already stated, the working pressure in the refrigerator must depend upon the extent of the reduction in temperature desired, 
bearing in mind that, the higher the pressure, the greater will be the work that can be got out of any given capacity of pump. The liquefying pressure in the condenser depends on the temperature of the cooling water and on the quantity that is passed through in relation to the quantity of heat carried away; and this pressure determines the mechanical work to be expended. In any given machine the work may be accounted for as follows:-

Friction.

Heat rejected during compression.

Heat acquired by the refrigerating agent in passing through the pump.

Work expended in discharging the compressed vapour from the pump.

Against which must be set-

Work done by the vapour entering the pump.

Assuming that vapour alone enters the pump, the heat rejected in the condenser is :-

Heat of vaporisation acquired in the refrigerator, with the correction necessary for difference in pressure.

Heat acquired in the pump, less the amount due to the difference between the temperature at which liquefaction occurs and that at which the vapour entered the pump, and less also the amount lost by radiation and conduction between the pump and the condenser.

Though circumstances vary so much that no absolutely definite statement can be made as to the working of ether machines in general, the following particulars, taken from actual experiment in this country, will serve to show what may be expected under ordinary conditions :- -

Production of ice, per twenty-four hours . . . . 15 tons.

$" \quad "$ per hour . . . . . . $1400 \mathrm{lbs}$

Heat abstracted in ice-making, per hour . . . . 245,000 units.

Indicated horse-power in steam cylinder, excluding that required for circulating the cooling water and for working cranes \&c. . . . . . . . . . . 83 I.H.P.

Indicated horse-power in ether pump . . . . . $46 \frac{1}{2}$ I.H.P. Thermal equivalent of work in ether pump, per hour . . 119,261 units. Ratio of work in pump to work in ice-making . . . 1 to 2.05 Temperature of water entering condenser . . . $\quad 52^{\circ} \mathrm{Fahr}$. 
Assuming the coal consumption per indicated horse-power to be 2 lbs. per hour, and the price of coal 15s. a ton, the total cost of producing transparent block ice in this country on the ether system with such a machine as that just referred to may be taken at about $5 s$. per ton, excluding allowance for repairs and depreciation. The production of ice would be about $8 \cdot 3$ tons per ton of coal.

For cooling water and other liquids, a similar machine is used to that shown in Figs. 6 and 7, Plate 54; but in this case the ice boxes are dispensed with, the liquid being passed direct through the refrigerator without the employment of brine.

Methylic ether, a liquid with a latent heat of vaporisation of 473 and which boils under atmospheric pressure at $10.5^{\circ}$ below zero Fahr., has been employed by Tellier in apparatus of practically similar design to that used with ordinary ether. Its curve of vapour tensions is shown in Fig. 1, Plate 52. Tellier's apparatus has never come into use in this country, and need not be further dwelt on; for beyond the difference in size of pump, and the obvious alterations due to the higher working pressures, it presents no features of importance not shown by the machine in Figs. 6 and 7, Plate 54.

Some years ago Raoul Pictet, of Geneva, successfully introduced sulphur dioxide as a refrigerating agent ; and in France a large number of his machines have been made and put to work. In this country also they have been used, but to a much smaller extent. The vapour tensions of sulphur dioxide are shown in Fig. 1, Plate 52. It is a liquid with a latent heat of vaporisation of 182 , and under atmospheric pressure boils at $14^{\circ}$ Fahr. This machine is also of similar design to those in which ether is employed; but Pictet combined the refrigerator with the ice-making tanks, the brine being circulated by means of a fan. In this way the space occupied was reduced, and the efficiency somewhat increased. The cost of producing ice by the Tellier and Pictet machines may be taken at practically the same as that by the ether process.

Some of the more volatile derivatives of coal tar have been used in compression machines, especially in the United States; but 
it will be unnecessary to refer to them in detail, as their application has been exceedingly limited.

Auhydrous ammonia, which may now be obtained as an article of commerce, has of late years been very largely introduced as a refrigerating agent, more especially in Germany and in the United States. Under atmospheric pressure anhydrous liquid ammonia boils at $37 \cdot 3^{\circ}$ below zero Fahr., and under this condition its latent heat of vaporisation is 900 . Its curve of vapour tension is shown in the diagram, Fig. 1, Plate 52. So far as the cycle of operation is concerned, it is precisely the same as for ether: the liquid is vaporised in the refrigerator by the action of the pump, which then compresses the vapour, and delivers it into the condenser at such pressure as to cause it to liquefy. In the construction of ammonia machines however there are two essential points of difference. For in the first place the pressure of the ammonia vapour is much higher than that of ether at the same temperatures, its tension at $60^{\circ} \mathrm{Fahr}$. being $108 \mathrm{lbs}$. per square inch; and secondly, owing to the action of ammonia on copper, no brass or gun-metal can be used in any part with which the gas or liquid comes into contact. One of the chief difficulties encountered in the compression of ammonia is leakage at the pump gland. The gas is extremely searching, and even at the comparatively low pressure of $30 \mathrm{lbs}$. per square inch above the atmosphere it will readily find its way through an ordinary gland; while at the pressure existing in the condenser, which may be taken at from 150 to 180 lbs. per square inch, this tendency is of course much aggravated. In order to minimise the leakage and to simplify the construction of the gland, the pumps are frequently made single-acting, as in this way the gland is exposed only to the refrigerator pressure, which is seldom above $30 \mathrm{lbs}$. It is also usual for glycerine, or some lubricant that does not saponify with ammonia, to be injected into the pump, so as to form a liquid seal for the gland, and in some cases for the piston as. well ; this is the general practice in the United States. In Germany, on the other hand, where the compression machine has been very largely applied, the double-acting pump is more usual. To lessen 
leakage, Linde provides a chamber in the gland box, into which glycerine or some suitable lnbricant is constantly forced at a slightly greater pressure than that prevailing in the condenser, so that the tendency is for the lubricant to leak inwards, instead of ammonia outwards. Any lubricant that does get into the pump passes out with the ammonia, and is separated from it in a suitable vessel. Up to the present time, so fow ammonia compression machines have been constructed in England, that as yet no general practice has been established; but on the whole the feeling seems to be in favour of the single-acting pump.

With regard to the other parts of the apparatus, but little need be said. Wrought-iron coils or zigzags are used for both the condenser and the refrigerator, their precise form depending on the fancy of the designer. The refrigerator is generally combined with the ice tanks, the cooling pipes being placed either below or at the side of the moulds, sometimes in a separate compartment and sometimes in the same tank. With the cell system shown in Fig. 9, Plate 54, an independent refrigerator is used, the cooled brine being circulated by a pump in a similar manner to that described for the ether system. Owing to the low temperature which may be attained by the use of ammonia, care has to be taken in the selection of a brine that will not congeal with the degree of cold to which it will be subjected. A solution of calcium or magnesium chloride in water is generally used.

The mechanical work expended in compressing ammonia may be accounted for in a precisely similar manner to that expended in the compression of ether. Notwithstanding that the degree of compression is so much greater with ammonia than with ether, the energy expended in compressing, heating, and delivering the gas is less, owing to the much smaller weight of ammonia required to produce a given refrigerating effect, the weights being in the inverse ratio of the heats of vaporisation, or as 1 to $5 \cdot 45$. For this reason the cost of making ice is much less with ammonia than with ether: one ton of coal being capable of producing as much as 12 tons of ice in well-constructed ammonia apparatus having a capacity of 15 tons per 24 hours. With coal at 15s. a ton, the cost of making ice by the 
ammonia compression system may be taken at about $38.9 d$. per ton for a production of 15 tons per 24 hours, exclusive of allowances for repairs and depreciation.

Through the courtesy of the manager of the Linde British Ice Co., the author is enabled to give the following results of a test made by a committee of Bavarian engineers with a machine erected in a brewery in Germany. The test he believes was carried out in an impartial manner; and though it is not put forward by the Linde Co. as showing the results attained in the ordinary working of their machines, it will nevertheless be of interest as indicating what may be expected under the most favourable conditions.

\begin{tabular}{|c|c|c|c|c|}
\hline \multicolumn{5}{|c|}{ Nominal capacity of machine, ice per 24 hours } \\
\hline Actual production of ice, per 24 hours & & & . & $39 \cdot 2$ tons. \\
\hline & & & - & \\
\hline Heat abstracted in ice-making, per hour & & & & \\
\hline \multirow{2}{*}{\multicolumn{5}{|c|}{$\begin{array}{l}\text { Indicated horse-power in steam cylinder, excluding that required } \\
\text { for circulating the cooling water and for working cranes \&c. }\end{array}$}} \\
\hline & & & & \\
\hline adicate & & & & 38 I.H. \\
\hline Ther & & , per hour & & 97,46 \\
\hline atio & & . & . & 1 to 7 \\
\hline tal feed-water u & & & & $26,754 \mathrm{lbs}$. \\
\hline
\end{tabular}

Ratio of coal consumed to ice made, taking an evaporation of

$8 \mathrm{lbs}$. of water per lb. of coal . . . . . . 1 to $26 \cdot 3$

In this case the pumps were driven by a Sulzer engine, which developed one indicated horse-power with $21 \cdot 8$ lbs. of steam per hour, including the amount condensed in steam pipes.

Ammonia compression machines are manufactured in this country by Messrs. Siebe Gorman and Co., whose apparatus is shown in Figs. 10 and 11, Plate 55; by the Birmingham Refrigeration Co.; and by the Linde British Ice Co.

System C.-This is known as the absorption process, and was first applied by Carré about 1850. The principle employed is chemical or physical rather than mechanical, and depends on the fact that many vapours of low boiling-point are readily absorbed by water, but can be separated again by the application of heat to the mixed liquid. A considerable number of machines in which ammonia 
was used in combination with water as an absorbent were made by Carré in France; but no very high degree of perfection was arrived at, owing to the impossibility of getting an anhydrous product of distillation : the ammonia distilled over containing about 25 per cent. of water, which caused a useless expenditure of heat during evaporation, and rendered the working of the apparatus intermittent.

In 1867 Rees Reece, taking advantage of the fact that two vapours of different boiling-points, when mixed, can be separated by means of fractional condensation, brought out an absorption machine in which the distillate was very nearly anhydrous. The action of the machine was briefly as follows. Ordinary liquid ammonia of commerce, of 0.880 specific gravity, was heated, and a mixed vapour of ammonia and water was driven off. By means of vessels termed the analyser and the rectifier, the bulk of the water was condensed at a comparatively high temperature, and run back to the generator; while the ammonia passed into a condenser, and there assumed the liquid form under the pressure produced by the heat in the generator, and the cooling action of water circulating outside the condenser tubes. The nearly anhydrous liquid was then utilised in a refrigerator in the ordinary way; but instead of the vapour being drawn off by a pump, it was absorbed by cold water or weak liquor in a vessel called an absorber, which was in communication with the refrigerator; and the strong liquor thus formed was pumped back to the generator, and used over again.

This apparatus was afterwards improved by Stanley, who introduced steam coils for causing the evaporation in the generator; and then by Pontifex and Wood, who have succeeded in bringing the absorption machine to a considerable state of efficiency. Their apparatus, as applied to the cooling of liquids, is shown in Fig. 5, Plate 53. $G$ is the generator, containing the coils, to which steam is supplied from an ordinary boiler not shown; $S$ is the analyser; $D$ the rectifier and condenser; $R$ the refrigerator or cooler, in which the nearly anhydrous ammonia obtained in the condenser is allowed to evaporate; A the absorber, through which weak liquor from the generator continually flows and absorbs the anhydrous vapour produced in the refrigerator; $\mathbb{E}$ the economiser or interchanger, by 
means of which the cold strong liquor from the absorber is heated by the hot weak liquor passing from the generator to the absorber; and $\mathbf{P}$ are the pumps for forcing the strong liquor produced in the absorber back into the analyser, where, meeting with steam from the generator, the ammonia is again driven off: the process being thus carried on continuously.

Assuming the action of the economiser to be perfect-which of course is a condition never met with in practice-all the heat given out by the steam in the generator coils would be found in the water issuing from the condenser, less that portion directly lost by radiation and conduction. In this case the total heat expended would be that required to vaporise the ammonia, and the water, which in the form of steam unavoidably passes off with the ammonia to the rectifier and condenser; plus the heat lost by radiation and conduction. In the refrigerator the liquid ammonia in becoming vaporised will take up the precise quantity of heat that was given off during its cooling and liquefaction in the condenser, less the amount due to difference in pressure, and less also the small amount due to the difference in temperature between the vapour entering the condenser and that leaving the refrigerator. Again, when the vapour enters into solution with the weak liquor in the absorber, the heat taken up in the refrigerator is given to the cooling water, subject to slight corrections for differences of pressure and temperature. Supposing there were no losses therefore, the heat given up by the steam in the generator, plus that taken up by the ammonia in the refrigerator, would be precisely equal to the amount taken off by the cooling water from the condenser, plus that taken off from the absorber. The sources of loss are:-

Inefficiency of the economiser.

Radiation and conduction from all vessels and pipes that are above normal temperature.

Useless evaporation of water which passes into the rectifier and condenser.

Conduction of heat into all vessels and pipes that are below normal temperature. Water passing into the refrigerator along with the liquid ammonia.

It will have been seen that the heat demanded from the steam is very much greater in the absorption system than in the compression. 
This is chiefly due to the fact that in the absorption system the heat of vaporisation acquired in the refrigerator is rejected in the absorber: so that the whole heat of vaporisation, required to produce the ammonia vapour prior to condensation, has to be supplied by the steam. In the compression system, the vapour passes direct from the refrigerator to the pump, and power has to be expended merely in raising the pressure and temperature to a sufficient degree for enabling liquefaction to occur at ordinary temperatures. On the other hand a great advantage is gained in the absorption machine by using the direct heat of the steam, without first converting it into mechanical work; for in this way its latent heat of vaporisation can be utilised by condensing the steam in the coils and letting it escape in the form of water. Each $1 b$. of steam passed through can thus be made to give up some 950 units of heat; while in a steam engine using 2 lbs. of coal per indicated horse-power per hour, about 160 units only are ntilised per lb. of steam, without allowance for mechanical ineffiency. In the absorption machine also the cooling water has to take up about twice as much heat as in the compression system, owing to the ammonia being twice liquefied, namely once in the condenser and once in the absorber. It is usual to pass the cooling water first through the condenser and then through the absorber.

The cost of producing clear block ice in this country, with an absorption machine of 15 tons capacity per 24 hours, may be taken at about $4 s$. per ton, with good coals at $15 s$. per ton, exclusive of allowance for repairs and depreciation. About 10 tons of ice can be made per ton of coal consumed, assuming an evaporative duty of 8 lbs. of water per $1 \mathrm{~b}$. of coal.

System D.-In this, which is known as the binary absorption system, liquefaction of the refrigerating agent is brought about partly by mechanical compression and partly by absorption; or else the refrigerating agent itself is a compound of two liquids, one of which liquefies at a comparatively low pressure, and then takes the other into solution by absorption. 
An apparatus of the first kind was brought out in 1869 in Sydney by Messrs. Mort and Nicolle, who used ammonia, with water as an absorbent. The machine consisted of an evaporator or refrigerator, a pump, and an absorber. The evaporator was supplied with strong ammonia liquor, which was vaporised by means of the reduction of pressure induced by the pump, and so abstracted heat from the liquid to be cooled. The weak liquor passing out at the bottom of the evaporator. was led by pipes to the pump, where it met with the ammonia vapour, along with which it was forced through cooling vessels under sufficient pressure to cause the solution of the ammonia; and the strong liquor thus formed was again passed into the evaporator. . This machine was only used by the inventors in Australia, so far as the author is aware; and he has no particulars as to fuel consumption or cost of working. It was not likely however to be a very economical apparatus, because the whole of the water entering the evaporator with the ammonia had to be reduced in temperature, giving up its heat to the ammonia vapour, and to that extent preventing the performance of useful cooling work. But this disadvantage was in some degree compensated for by reducing the temperature of the strong liquor before it entered the evaporator, by means of an interchanger, through which the very cold weak liquor passed on its way to the pump.

In machines of the second kind, in which both liquids are evaporated at a low temperature, the foregoing objection does not exist; and though this mode of working has not as yet been introduced into this country, it has been successfully employed in the United States for several years by Messrs. De Motay and Rossi. Tho liquid used is a mixture of ordinary ether and sulphur dioxide, and has been tormed ethylo-sulphurous dioxide: its adoption being decided on after a series of experiments with numerous other combinations of ethers and alcohols with acids. In these investigations it was found that liquid ether at ordinary temperatures possessed an absorbing power for sulphur dioxide amounting to some 300 times its own volume; while at $60^{\circ} \mathrm{Fahr}$. the tension of the vapour given off from the binary liquid was below that of the atmosphere. In working, both liquids evaporate in the refrigerator, under the 
influence of the pump; and in the condenser the pressure never exceeds that necessary to liquefy the ether. The compressing pump has less capacity than would be required for ether alone, but more than for pure sulphur dioxide. The author has no particulars as to the cost of making ice by this process; but he believes it to be somewhat less than with ether.

An interesting application of the binary system has lately been made by Raoul Pictet, who found that by combining carbon dioxide and sulphur dioxide he could obtain a liquid whose vapour tensions were not only very much less than those of carbon dioxide, but were actually below those of pure sulphur dioxide at temperatures above $78^{\circ} \mathrm{Fahr}$. The curve for Pictet's liquid is shown in the diagram, Fig. 1, Plate 52. This is a most remarkable and unlooked-for result, and may open up the way for a much greater economy in ice production than has yet been attained. As to the results that have been obtained with this process, the author has no definite particulars; but he understands it is stated to give a production of 35 tons of ice per ton of coal.

\section{Machinery by whrch a Gas is Compressed,}

partialiy CoOled While under gompression, AND FURTher Cooled by SUBSEQUent Expansion.

This subject having been dealt with in a paper on "Machines for producing Cold Air" which the author had the honour to read before the members of this Institution in Janviary 1881, the remarks under this head will therefore to a large extent be supplementary to that paper, and will refer chiefly to improvements which have been effected since that date. It will be convenient however, and will tend to a better appreciation of the subject, to present concisely some brief considerations respecting the physical laws relating to this system of refrigeration, even at the risk of repeating part of the matter touched upon in the previous paper.

The intrinsic energy of a permanent gas, or its capacity for performing work, depends entirely upon its temperature. Increase of pressure imparts no additional energy, but merely places the gas in such a condition relatively to some other pressure as to enable 
advantage to be taken of its intrinsic energy by expansion. Thus a pound of air at ordinary atmospheric pressure has the same intrinsic energy as a pound of air at 50 lbs. pressure above the atmosphere, so long as their temperatures are the same; but in the former case no part of the energy can be made use of by expansion without the removal of at least a part of the equal and opposite resistance of the atmosphere, while in the latter case expansion can take place freely until the pressure is reduced to that of the atmosphere. As mechanical work and heat are mutually convertible, it is obvious that, if during expansion a gas is caused to perform work on a piston, its supply of heat must be drawn on to an extent measured by the thermal equivalent of the work done, provided no extraneous source of heat exists from which the deficiency can be made good; and the gas after expansion will be colder than it was before expansion. Expansion behind a piston without the addition of heat from any extraneous source is called adiabatic expansion; and the following are the relations between temperature, volume, and pressure for any two points in the same adiabatic curve:-

$$
\frac{t}{\bar{t}_{1}}=\left(\frac{v_{1}}{v}\right)^{\gamma-1}=\left(\frac{p}{p_{1}}\right)^{\frac{\gamma-1}{\gamma}}
$$

where $t$ and $v$ and $p$ denote absolute temperature, volume, and absolute pressure before expansion, and $t_{1} v_{1} p_{1}$ those after expansion, while $\gamma$ is the ratio of the specific heat under constant pressure to that with constant volume. The results with regard to the expansion of dry air are shown graphically by the curve $E$ F in Fig. 2, Plate 52: E D representing the initial volume at a pressure of 50 lbs. per square inch above the atmosphere and at a temperature of $70^{\circ} \mathrm{Fahr}$, which is expanded down to the volume F B at atmospheric pressure, the temperature falling to $-115^{\circ} \mathrm{Fahr}$. owing to the performance of the mechanical work represented by the area E F I K.

During adiabatic compression, the converse results take place, and the same relations exist between absolute temperature, volume, and absolute pressure, as during expansion: $t_{1} v_{1} p_{1}$ denoting those 
before compression, and $t v p$ those after compression. On the diagram this is shown graphically by the curve $\mathrm{A} \mathrm{C}$, which is the adiabatic for the compression of the initial volume $A$ B at atmospheric pressure and $70^{\circ}$ Fahr., to 50 lbs. per square inch above the atmosphere, the temperature rising to $354^{\circ} \mathrm{Fahr}$. owing to the acquirement of heat due to the performance of the mechanical work represented by the area A G J C. A E is the line of isothermal compression and expansion between the two points $\mathrm{A}$ and $\mathrm{E}$.

In the succeeding remarks reference will be made to the use of ordinary atmospheric air alone; for although in one or two special instances this class of machinery has been applied to the cooling of some of the more volatile hydro-carbons, its almost universal application at the present time is for the cooling of air, which therefore will alone be dealt with.

The amount of aqueous vapour present in the atmosphere varies from that required to produce saturation down to about one-fifth of that quantity. At any given temperature a volume of saturated air can contain only one definite amount of vapour in solution; and if from any cause additional moisture be present, it cannot exist as vapour, but appears as water in the form of fog or mist. The temperature of saturation, or dew point, varies according to the quantity of vapour in solution: the smaller the quantity, the lower being the dew point. The capacity of air for holding moisture is also affected by pressure: a diminution in rolumo under constant temperature reducing this capacity in direct proportion.* In the former paper reference was made to various means that had been devised for ridding the air more or less completely of its contained moisture, in order to obviate as much as possible the practical evils resulting from its condensation and freezing: this being at that time considered one of the most important points in the construction of cold-air machinery. Since then however experience has demonstrated that these evils were

* For the quantity of vapour necessary to produce saturation, reference may be made to the table and formula given in the appendix to the paper on "Machines for producing Cold Air" (Proceedings 1881, page 122). 
much exaggerated, and that the condensation of the vapour and deposition of the moisture in the ordinary cooling process after compression, which is common to every cold-air machine, are amply sufficient to prevent any serious deposition of ice about the ralves and in the air passages: provided firstly that these valves and passages are well proportioned, and secondly that proper means are adopted for obtaining in the coolers a deposition of the condensed vapour, which would otherwise pass with the air into the expansion cylinder in the form of fog, and become converted into ice. Reference to the table shows that, if the compressed air be thoroughly deprived of its mechanically suspended moisture, the amount of vapour entering the expansion cylinder is extremely small. Another matter from which the mystery has now been dispelled is the meaning of the term " $\mathrm{dry}$ " air, so much used by the makers of cold-air machinery : this being a point that was just touched upon towards the close of the discussion upon the previous paper. No doubt it is still to a large extent popularly supposed that, unless the air be subjected in the machine: to some special drying process, it will be delivered from the expansion cylinder in a moist or damp state, and in consequence be unfitted for nse in the preservation of perishable food and for other purposes. But no such state could really exist; for whether the air be specially "dried" or not, its humidity when delivered from the expansion cylinder is precisely the same, so long as its temperature and pressure remain the same, inasmuch as in practice it is always in a saturated condition for that pressure and temperature. The difference lies in the amount of ice formed, which of course is greater if the amount of moisture entering the expansion cylinder is greater; but this quantity, as has been already stated, may in the author's opinion be brought down within perfectly convenient limits by a proper construction of the cooling vessels. In his latest machines therefore all special drying apparatus has been dispensed with: the air being simply compressed, passed through a surface cooler, and expanded back to atmospheric pressure. On the other hand Messrs. Haslam and Co. of Derby, and Messrs. J. and E. Hall of Dartford, still apply an interchanger, on somewhat the same principle as that previously described in connection with the Bell-Coleman machine. 
(Proceedings 1881, page 111); and it would be interesting if some definite particulars could be furnished to show what practical effect this interchanger really has.

Messrs. Hall's cold-air machine is of both horizontal and vertical type, the latter applying to the smaller sizes. In either case, when combined with a steam engine, it consists of three double-acting cylinders placed side by side, at the end of a frame or bedplate; the cylinders are furnished with the usual moving parts, and the connecting-rods work on three crank-pins on a common crank-shaft. One of the cylinders is used with steam in the ordinary manner, for giving the requisite motive power. Of the two others, one is for compressing and one for expanding the air. The coolers are of the multitubular type for surface cooling, and are placed below the bedplate or frame, an interchanger being also provided for still further reducing the temperature of the compressed air, by the action of the spent air from the storage chambers. The valves for the compression and expansion cylinders are slides of somewhat peculiar design, worked from a pair of weigh-bars, one for the main and the other for the expansion slides. The valves are usually placed on the under-side of the cylinders, which renders them rather difficult of access; but in the larger sizes of machines the cylinders are raised, and work down to the shaft at an angle, which gives a little more room below. In some of the later machines the valves are placed above the cylinders. The compressor is water-jacketed.

The Haslam dry-air refrigerator, which has been very largely adopted, is also made both horizontal and vertical, the horizontal type applying to large machines, as shown in Figs. 12 and 13, Plate 56, and the vertical to those of small size. The cylinders are double-acting, and their arrangement with regard to one another varies in different classes of machines. The compressor $\mathrm{C}$ is water-jacketed, and discharges into surface coolers $R$ placed in the bed. The compressed air, after having been cooled in the ordinary way by water, is further reduced in temperature in an interchanger, by the action either of the spent cold air on its way from the chamber in which it has been utilised, or of the cold air as it leaves the expansion cylinder $\mathrm{E}$; and in this manner a further 
condensation and deposition of moisture are brought about. The expansion cylinder $\mathbf{E}$ presents no peculiarity in design, with the exception of the exhaust valves, which are separate from those admitting the air, and are so arranged as to offer as little obstruction as possible to the passage of the air. The Haslam Co. also manufacture the Bell-Coleman machine, which was described in the author's previous paper (Proceedings 1881, page 111).

A horizontal dry-air refrigerator of the author's design, of the type used for delivering from 20,000 to 60,000 cubic feet of cold air per hour, is shown in Figs. 14 and 15, Plate 57 ; and a section through the compression and expansion cylinders and valves is given in Fig. 16. The compressor $\mathbf{C}$ is double-acting, and the expansion cylinder $\mathbf{E}$ single-acting. They are placed close together, tandem fashion, leaving room for examination of the piston, with one rod common to both cylinders. In this way the coldest part of the expansion cylinder is removed from the hottest part of the compressor. The air-valves, shown black in the section, Fig. 16, are circular slides of phosphorbronze, actuated by eccontrics in the usual way. This kind of valve enables the ports to be made rery short and direct; and besides being noiseless in action, it allows of a high piston-speed being attained. No trouble has been experienced with regard to wear, not a single case having occurred in which the valves have had to be replaced, notwithstanding that some have been in almost constant work since 1882. The air enters the compressor $\mathrm{C}$ by the pipes $\mathrm{A}$, and after being compressed passes by the pipe $B$ to the coolers $R R$, which are placed in the bedplate, and consist of a couple of iron vessels containing clusters of solid-drawn Muntz-metal tubes of $\frac{3}{4}$-inch external diameter. Water is circulated through the inside of the tubes by the pump $P$, the supply passing in by the pipe $D$, through the tubes, and away by the pipe $F$ to the compressor jacket, whence it escapes by the pipe $H$. The water condensed and deposited from the air in the coolers is blown off from time to time by means of drain cocks, or may be discharged automatically. The compressed air passes through one cooler and returns through the second, being cooled to within some $5^{\circ}$ or $6^{\circ}$ 
of the initial temperature of the cooling water, which circulates in a direction opposed to that of the air. The quantity of water required is at the rate of from 30 to 40 gallons for every 1000 cubic feet of cold air discharged, that is, from three to four times the weight of the air; but the quantity varies in different machines according to the efficiency of the apparatus. From the coolers, the air passes by the pipe $I$ to the expansion cylinder $E$; and after performing work upon the piston, and returning about 60 per cent. of the power expended in its compression, it is exhausted from the passage $K$, having become cooled down to from $70^{\circ}$ to $90^{\circ}$ below zero Fahr. The steam cylinder $\mathrm{L}$ is overhung from strong brackets cast on the bedplate, and is arranged so that a jet or surface condenser can be placed below, with an air-pump worked from a continuation of the pistonrod; the space occupied is thus practically the same, whether the engine is non-condensing, as shown in Plate 57, or condensing. The arrangement also lends itself readily to the application of a second steam cylinder, tandem fashion, for working on the compound principle, as shown in Figs. 17 and 18, Plates 58 and 59. In this case the surface-condenser $\mathrm{C}$ is placed below the high-pressure cylinder $\mathrm{H}$, the air-pump $\mathrm{P}$ being driven from a crank-pin fixed in the fly-wheel. The same water serves buth for cooling the air and for condensing the steam, passing first through the coolers $R$, and then through the surface-condenser $\mathrm{C}$.

For land machines to deliver more than 60,000 cubic feet of cold air per hour, the vertical typo is adopted, and the compressor is made single-acting as well as the expansion cylinder, while a horizontal compound condensing steam-engine is used for giving the necessary motive power. A machine to deliver 285,000 cubic feet of cold air per hour, for cooling a large market, is now being designed in this way. The compressor is furnished with an internal pipe, from which a spray of cold water continually plays on the back of the piston and on the sides of the cylinder, but never comes in contact with the air itself.

In order to secure compactness and simplicity, all machines delivering less than 20,000 cubic feet of cold air per hour are made of the type shown in Figs. 19 and 20, Plate 60, the compressors 
keing single-acting. A section through the air cylinders of such a machine is given in Fig. 21. The smaller sizes are very frequently made on the vertical plan, for use both on land and on board ship. A steam-driven vertical machine is shown in Figs. 22 and 23, Plate 61. The design is practically the same as that of the horizontal machines; but in the vertical type the coolers $R$ are cast in one piece with the frame, instead of being separate. In Figs. 24 and 25 is shown a vertical machine of similar design, but arranged for being driven by a belt.

The main objects kept in view by the author in designing all the foregoing machines are:-economy of production, efficiency, and simplicity. Some thirty of these refrigerators of one form or the other have now been made and put to work since 1884; and in not one single instance has any breakdown occurred in working, nor have any repairs been required beyond those that would have been necessary to an ordinary steam engine of good construction. In many cases machines made in England have been packed and shipped to Australia, and to North and South America and other foreign countries, where they have been erected and put to work without the assistance of any skilled labour from this country.

With regard to the power expended in cooling air on this plan, it may be stated that, in the best machines of large size now made, a weight of 1000 lbs. of air per hour can be reduced from $60^{\circ}$ above to $80^{\circ}$ below zero, with cooling water at $60^{\circ}$ Fahr., with the expenditure of about 18 indicated horse-power. This is equal to an absiraction of 916 units per $\mathrm{lb}$. of coal, with an engine using 2 lbs. of coal per indicated horse-power per hour.

\section{Considerations as to the}

Applications of the Varrods Systemrs.

Under this head it is not intended to deal with the class of apparatus first described - for abstracting heat by the rapid melting of a solid: inasmuch as, excepting for domestic purposes in localities where other ice is not available, its application is wholly special and very limited, being confined almost entirely to the laboratory. Nor in regard to the machinery and apparatus in the 
second class-for abstracting heat by the evaporation of a more or less volatile liquid - need much be said, so far as ice-making and ordinary cooling are concerned; the various systems have already been explained in considerable detail, and sufficient information has been given upon which to base an estimate as to their economical application under any stated conditions. It is therefore chiefly with the machinery described in the third class that the present considerations will deal:-namely machinery by which a gas is compressed, partially cooled while under compression, and further cooled by subsequent expansion in the performance of work.

Probably the earliest application of a refrigerating machine to manufacturing purposes was in 1861, when one of Harrison's ether machines was used by $\mathrm{Mr}$. A. C. Kirk for the extraction of solid paraffin from shale oil. Since then the manufacture of paraffin has been developed to a large extent, and at the present time there are very few works engaged in its production without a refrigerating machine of one kind or another.* For the cooling of worts and of fermenting beer in breweries, refrigerating machines are largely employed. With English beer, which it is not necessary to cool below $50^{\circ} \mathrm{Fahr}$., the general practice is to reduce the temperature of the cooling liquor by passing it through the refrigerator of the machine, the cooled liquor being afterwards used in an ordinary brewer's refrigerator. For lager beer however, which is fermented at about $40^{\circ} \mathrm{Fahr}$., the liquor is generally cooled by means of brine, and the temperature is brought down nearly to freezing-point. The same machine is in this country frequently employed for circulating cooled brine through a series of pipes above the fermenting tuns as well as for cooling the liquor; while in lager-beer breweries the whole of the fermenting rooms and stores are kept, the former at about $42^{\circ} \mathrm{Fahr}$., and the latter at about $38^{\circ}$ Fahr., by means of cold brine circulating through pipes placed either on the ceiling or around the walls.

* Full information in regard to the most recent practice in.paraffin cooling will be found in the Journal of the Society of Chemical Industry, 29 May and 30 Nov. 1885, which contains papers by Mr. Beilby describing the cooling machinery erected at the Oakbank Oil Works. 
For breweries, as well as for paraffin extraction, there can be no doubt that the most suitable machines to employ are those in which the cold is produced by the evaporation of a volatile liquid. Notwithstanding this, air-refrigerating machines have been applied for both purposes in certain special cases, and have given good results, though at a larger expenditure of fuel. There are many instances however in which the extra cost of fuel may be more than counterbalanced by the advantages resulting from simplicity and compactness, and from the absence of all inflammable or corrosive chemicals. Besides this the facility of application of cold-air machines is much beyond that of any other refrigerator. For these reasons they have been applied in dairies, and in butterine works : in the latter case an additional advantage being gained from the rapidity with which the cooling can be accomplished, owing to the extremely low temperature at which the air is delivered from the machine.

The most extensive application of dry-air refrigerators however has been to the preservation of meat and other perishable foods. Explanations with regard to the general question of preservation by cold have already been fully gone into by the author in a paper on the "Preservation of Foods by Cold" read before the Health Congress at Brighton in December 1881; and it will therefore suffice here to state that, although it had long been known that at low temperatures the decomposition of animal matter was arrested for an almost indefinite period, yet the practical realisation of preservation by cold was prevented from being carried out for want of a simple and efficient means of artificial refrigeration. The attempts that had been made to produce a refrigerated atmosphere by means of ice had not given satisfactory results, owing no doubt to the moist state of the air, which, cooled by contact with melting ice, was necessarily saturated, and brought about a musty taste and loss of flavour in the meat preserved in it. In 1878 however, upon the successful development of the cold-air machine, it became possible to produce a cold atmosphere, which even at a temperature of from $35^{\circ}$ to $40^{\circ}$ never contained more than from 50 to 60 per cent. of the moisture required to saturate it. Under this condition all danger from excess of moisture as well as from excessive dryness was 
avoided; and the dry-air refrigerator was therefore speedily adopted for preservative purposes.

Machines in which cold is produced by the evaporation of a volatile liquid have also been applied for preserving perishable foods. This has been done, either by cooling the rooms direct by means of overhead pipes through which the cooled brine is circulated; or else by causing a current of air from a fan to impinge against surfaces cooled by an internal circulation of brine, and by then passing the cooled air into the storage rooms.*

As to whether the air machine or that employing a volatile liquid is the best and most suitable, no general rule can be laid down. The simplicity, compactness, and readiness of application of the former have secured it a ready adoption in many cases where chemical machines would have been wholly inadmissible; but on the other hand the author considers that air machines have frequently been entirely misapplied. For use on board ship there can probably be no difference of opinion; and nearly the whole of the meat now imported into this country in a cooled or frozen condition is preserved by means of dry-air refrigerators, while in only one or two cases is a portion of it chilled and frozen on land by chemical machines.

The means adopted for the freezing and preservation of meat are very simple. They consist in lining the room, or the hold of the vessel, with material as impervious to heat as practicable. The construction of the lining is altered in different cases according to circumstances and to fancy; but it may be taken that an outer and inner layer of tongued and grooved boards 1 inch or $1 \frac{1}{2}$ inches thick, with a 9-inch space between filled with charcoal, form a fairly good protection; while in some cases silicate cotton may be used with advantage instead of charcoal. A little extra care and expense bestowed on the insulation of a chamber are soon repaid; for when the contents of the chamber are once reduced to the required temperature, the refrigerating machine has nothing further to do than to neutralise

* An apparatus on the latter plan by Mr. Chambers of New Zealand was fully described and illustrated in "The Engineer" of 14 August 1885, page 130. 
the heat passing through the walls: so that, the more perfect the insulation, the greater is the saving in fuel, in wear and tear of machinery, and in attendance. The cold air from the machine is usually admitted by ducts placed near the ceiling; and after performing its cooling work it is led back to the compressor, to be used over again with the addition of a small amount of fresh air. In freezing, a temperature of about $10^{\circ} \mathrm{Fahr}$. or even lower should be maintained, and the carcasses should be hung so that the air can circulate freely around them. If however the meat has previously been frozen, as is generally the case with the cargoes brought from abroad, which are to a large extent frozen on shore, the carcasses are best packed as close together as possible, taking care to avoid injury through bruising, and to see that a free space is left for the cold air to circulate between the meat and the inner lining of the chamber. The temperature in this case need only be maintained low enough to leave a sufficient margin in case of the machinery having to be stopped for any slight adjustment or for oiling.

The capacity of a machine to be applied in any given case is determined by a consideration first of the cooling work to be performed on the material contained in the chamber; and secondly of the amount of heat that will pass into the chamber from without. With regard to the first, nothing need be said here. The second quantity depends upon the area of the walls, floor, and ceiling, their construction, and the difference between the minimum internal and maximum external temperature. Experience has of course laid down certain general rules; but there are always special cases arising which require special treatment, and which can only be considered on the basis here set forth.

The trade in frozen meat has already necessitated the establishment of large stores, where the carcasses are received and kept until they are required for consumption. A number of retail butchers also are now adopting cold stores of their own; and in Fig. 26, Plate 62, is shown in section such a storage arrangement carried out in the vaults in Leadenhall Market for the preservation of about 20 tons of meat, partly frozen and partly unfrozen. A vertical dry-air machine, such as is shown in Figs. 24 and 25, 
Plate 61 , is driven by an Otto gas engine, and by working from three to six hours per day supplies sufficient cold air for the four chambers. The temperature rises a few degrees during the night, and between Saturday night and Monday morning; but this is not found to be any disadvantage, and it has never yet been necessary to run the machine on a Sunday. The same water that is used for cooling the air cools also the gas-engine cylinder, and is afterwards used for heating the offices. The cost of the gas in this case is $1 s$. $3 d$. per hour. In view of the increasing demand for installations of this kind, the author has made arrangements with Messrs. Crossley Brothers to manufacture his dry-air machine in combination with the Otto gas engine, in a form somewhat similar to that shown in Figs. 19 and 20, Plate 60, the gas engine simply taking the place of the steam engine there shown. In this way the cost will be reduced; and space also, which is generally very limited, will be saved. Similar installations to that shown in Fig. 26, Plate 62, have been erected for poulterers, game dealers, and butter salesmen, but need not be further referred to.

In addition to the importation of dead meat, refrigerating machines of the horizontal kind shown in the diagrams have been applied for supplying fresh cool air for the ventilation of ships' holds in which live cattle are carried. In this way a temperature of $100^{\circ}$ Fahr. has been reduced to $70^{\circ}$ in the height of summer, and the loss of cattle has been entirely prevented. No doubt the same system could be equally well applied for the cooling and ventilation of buildings; but so far as the author is aware it has not yet been tried.

In Fig. 27, Plate 62, is shown a plan, partly in section, of an arrangement on board a passenger vessel for making ice, preserving meat, game, fish, vegetables, and other perishable foods, and cooling water, wine, beer, aërated waters, \&c. This is a plan frequently carried out in large passenger vessels, and was introduced, the author believes, by Mr. Manuel, the engineering superintendent of the Peninsular and Oriental Company. The particular arrangement illustrated is one adopted in connection with a vertical steam-driven machine such as that shown in Figs. 22 and 23, Plate 61. The course of the cold air is indicated by arrows. In case of the regetable 
room becoming too cold, ducts are provided by which the air can be led direct from the meat chamber to the machine. A somewhat similar arrangement of refrigerating plant is used in hotels; and the author's machines have been successfully applied for this purpose in the United States, though not as yet in this country.

A recent application, also worthy of notice, is for preserving fish on board steam-trawlers and on shore. Last year two of the author's vertical machines were supplied for this purpose, one on a steantrawler and one on a carrier, for use off the coast of Brazil, almost under the equator, in a climate where fish was hardly known as an article of diet, owing to the previously insuperable difficulties of preserving it in a sufficiently fresh state. The fish as soon as caught are placed on trays in an insulated room maintained at a temperature of about $35^{\circ} \mathrm{Fahr}$. The experiment has been perfectly successful, and a further order for similar machinery is now being executed.

In 1882 dry-air refrigerators were first applied to the cooling of chocolate by Messrs. J. S. Fry and Sons of Bristol, who adopted one of the anthor's horizontal machines with the double-expansion arrangement described in his previous paper. Since then a number of similar machines have been applied for the same purpose in different parts of Europe and in the United States ; and works which had to be entirely stopped in summer are now carried on during the whole year. The preservation of yeast, the cooling of gelatine dry plates, and of fresh-killed meat in slaughter houses, and the freezing of tongues in South America for exportation, have all been satisfactorily accomplished by the dry-air machine.

A rather remarkable application of refrigeration was made towards the close of last year by Captrin Lindmark, of the Swedish Royal Engineers, who was engaged in the construction of a tunnel for foot passengers through a hill in Stockholm, on the top of which were built residential houses, as shown in Fig. 30, Plate 63. The workmen came upon some ground, consisting of gravel mixed with clay and water, which had so little cohesion that the ordinary method of excavation had to be abandoned and the works stopped, owing to a subsidence in the earth above, which endangered the safety of the 
houses. Underpinning was out of the question, on account of the great expense. Under these circumstances it was decided to freeze the running ground, and to use cold air for the purpose as being most readily applied. One of the author's horizontal machines, capable of delivering 25,000 cubic feet of air per hour, was accordingly supplied by Messrs. Siebe Gorman and Co., and was erected in the tunnel as close as possible to the required spot. The arrangement is shown in Figs. 31 and 32. The innermost end of the tunnel next the face was formed into a freezing chamber by means of a partition wall $P$, which was made of a double layer of wood filled in between with charcoal. In the middle of last September the works were resumed. After the refrigerator had run for sixty hours continuously, the gravel was frozen into a hard mass to a depth varying from five feet near the bottom of the tunnel to one foot near the top. At the crown no freezing took place; and though the temperature at the bottom of the chamber was as low as $40^{\circ}$ below zero Fahr., a thermometer placed at the top, 16 feet above the floor, indicated $32^{\circ}$ above zero. This circumstance however was an advantage rather than otherwise, because in any case the roof would have had to be supported by planking, which would have been difficult to drive into the gravel had it been actually frozen at that part. The work was proceeded with in lengths of 5 feet, the excavation commencing at the top ; and a temporary iron wall $\mathrm{W}$ made up of plates 12 inches square, as shown in Fig. 32 and ales in Figs. 28 and 29, Plate 62, was built in against the face from the top downwards as the eutting away of the gravel proceeded. For 8 to 10 feet up from the bottom no protection was needed, as the frozen gravel formed such a hard solid mass that it had to be removed with special tools. After once fairly starting, it was sufficient to run the cold-air machine on the average from ten to twelve hours every night, excepting after heavy rains, when much water percolated through the gravel. The machine worked all the time without a single bitch, and delivered the air at a temperaturs of $67^{\circ}$ below zero Fahr. The temperature of the freezing chamber was generally from $6^{\circ}$ to $15^{\circ}$ below zero Fahr. after twelve hours' running; but it soon rose to freezing point when the men began to work. After two 5 -feet lengths had been excavated, 
the partition wall $\mathrm{P}$ was removed forward; the capacity of the freezing chamber thus varied from 3,000 to 6,000 cubic feet. The arching of the tunnel was completed as rapidly as possible close up to the temporary iron wall W, while the ground was still frozen. This method of driving the tunnel was employed through a distance of about 80 feet with entire success. In the residential house to the north, neither subsidence nor cracks were perceptible three months after the tunnel was completed at this point. In the house to the south, the front has subsided about an inch, causing some small cracks in the walls; but this house was not so well built as the other, subsidences having taken place in it before the tunnel was commenced. The daily progress while using the freezing process averaged about 1 foot.*

Although this is the first instance in which a dry-air refrigerator has been applied for the freezing of running ground, it is not the first in which refrigeration has been used for that purpose. As early as 1862 an ether machine was constructed by Messrs. Siebe Gorman and Co. for freezing a quicksand met with in sinking a well. In that case pipes formed into a coil of larger diameter than the lining of the well were sunk into the quicksand, which was then frozen solid by circulating cold brine through the pipes. The excavation was then proceeded with, the lining put in, the circulation of brine stopped, and the coil removed. The same plan has recently been adopted by Mr. Poetsch in Germany in connection with the sinking of colliery shafts; but instead of a coil, a series of vertical iron pipes are used, arranged in a circle, the effect of course being precisely the same. $\uparrow$ For driving the Stockholm tunnel however, it is difficult to see how freezing by means of brine could have been applied, the excavation being horizontal instead of vertical.

* A full description of the construction of this tunnel is given in "The Engineer" of 9 April 1886, page 282.

† Further particulars of Poetsch's process are given in "The Engineer" of 30 November 1883 , page 417. 


\section{TABLE 1.}

\section{Freezing Mixtures.}

Composition by weight.
Reduction of Temperature in degrees Fahr.

\section{Ammonium chloride}

Potassium nitrate .

Water .

Ammonium nitrate.

Water .

Ammonium chloride

Potassium nitrate .

Sodium sulphate

Water .

Sodium sulphate

Sulphuric acid diluted

Sodium sulphate

Hydrochloric acid .

Sodium nitrate

Nitric acid diluted.

Ammonium nitrate .

Sodium carbonate

Water .

Sodium sulphate

Ammonium chlorid

\section{P}

Nitric acid diluted.

Sodium phosphate

Nitric acid diluted .

Sodium sulphate

Ammonium nitrate .

Nitric acid diluted .

. $\left.\begin{array}{r}5 \text { parts } \\ 5 \% \\ 16 \%\end{array}\right\}$ From $+50^{\circ}$ to $+10^{\circ}=40^{\circ}$

- $\left.\begin{array}{l}1 \text { part } \\ 1,\end{array}\right\}$ From $+50^{\circ}$ to $+4^{\circ}=46^{\circ}$ - 5 parts

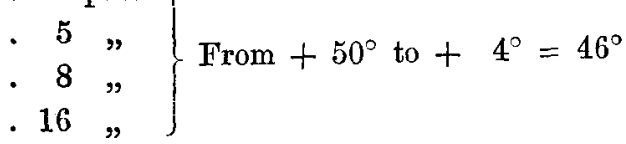
. $\left.\begin{array}{l}5 \text { parts } \\ 4,\end{array}\right\}$ From $+50^{\circ}$ to $+3^{\circ}=47^{\circ}$ - $\left.\begin{array}{l}8 \text { parts } \\ \text { - } 9,\end{array}\right\}$ From $+50^{\circ}$ to $0^{\circ}=50^{\circ}$ - $\left.\begin{array}{l}3 \text { parts } \\ 2 \%\end{array}\right\}$ From $+50^{\circ}$ to $-3^{\circ}=53^{\circ}$

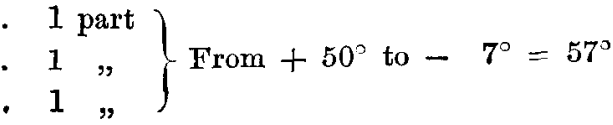

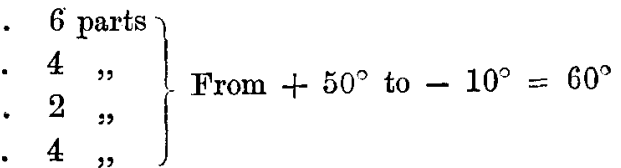
- $\left.\begin{array}{l}9 \text { parts } \\ 4,\end{array}\right\}$ From $+50^{\circ}$ to $-12^{\circ}=62^{\circ}$ - 6 parts

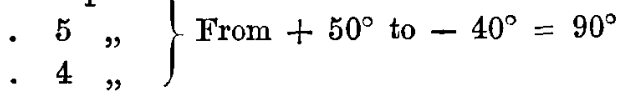
(see continuation on next page) 


\section{TABLE 1.-(continued)}

Freezing Mixtures.

\section{Composition by weight.}

Snow or pounded ice

Sodium chloride

Snow or pounded ice

Sodium chlorido

Ammonium chloride

Snow or pounded ice

Sodium ehloride .

Ammonium chloride

Potassium nitrate .

Snow or pounded ice

Sodium chloride

Ammonium nitrate .

Snow 3 parts

$\left.\begin{array}{l}2 \text { parts } \\ 1, y\end{array}\right\}$

Reduction of Temperature in degrees Fahr.

$$
\begin{aligned}
& \left.\begin{array}{l}
5 \text { parts } \\
\text { - } 2 \% \\
11 \%
\end{array}\right\} \\
& \text { To }-12^{\circ}
\end{aligned}
$$$$
\text { To }-5^{\circ}
$$

. 24 parts

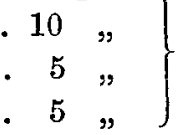

$$
\text { To }-18^{\circ}
$$

. 12 parts

$\left.\begin{array}{ll}5 & \\ . & 5\end{array}\right\}$

$$
\text { To }-25^{\circ}
$$

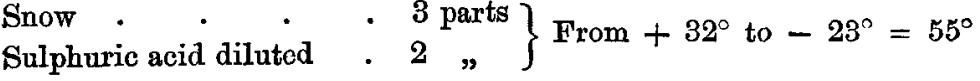

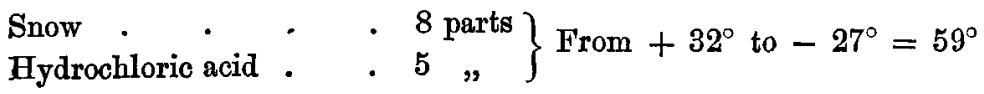

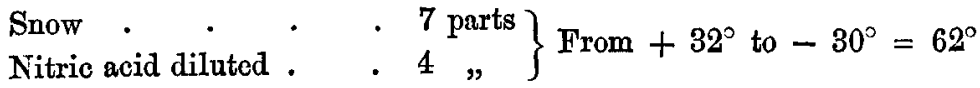

$\left.\begin{array}{lll}\text { Snow } . & \cdot & 4 \text { parts } \\ \text { Calcium chloride } & \cdot & 5 \%\end{array}\right\}$ From $+32^{\circ}$ to $-40^{\circ}=72^{\circ}$ $\left.\begin{array}{l}\text { Snow } \cdot \dot{ } \cdot \cdot \dot{2} \text { parts } \\ \text { Calcium chloride crystalised } \\ 3\end{array}\right\}$ From $+32^{\circ}$ to $-50^{\circ}=82^{\circ}$

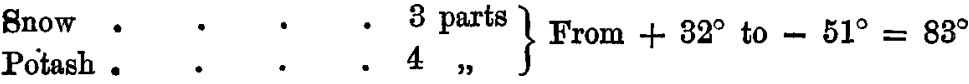




\section{TABLE 2.}

Evaporation of Liquids.

\begin{tabular}{|c|c|c|c|c|c|c|c|}
\hline Liquid or & Xas. & Water & $\begin{array}{c}\text { An- } \\
\text { hydrous } \\
\text { Ammonia }\end{array}$ & $\begin{array}{l}\text { Sul- } \\
\text { phuric } \\
\text { Ether }\end{array}$ & $\begin{array}{c}\text { Methylic } \\
\text { Ether }\end{array}$ & $\begin{array}{c}\text { Sul- } \\
\text { phur } \\
\text { Dioxide }\end{array}$ & $\begin{array}{l}\text { Pictet's } \\
\text { Liquid }\end{array}$ \\
\hline $\begin{array}{l}\text { Specific Grav } \\
\text { Vapour, com } \\
\text { with Air = }\end{array}$ & $\left.\begin{array}{l}\text { ty of } \\
\text { ared } \\
\cdot 000\end{array}\right\}$ & 0.622 & $0 \cdot 59$ & $2 \cdot 24$ & $1 \cdot 61$ & $2 \cdot 24$ & - \\
\hline $\begin{array}{l}\text { Boiling Poin } \\
\text { at atm. pr }\end{array}$ & ssure $\}$ & $\begin{array}{l}\text { Fahr. } \\
212^{\circ}\end{array}$ & $\begin{array}{l}\text { Fahr. } \\
-37 \cdot 3^{\circ}\end{array}$ & $\begin{array}{c}\text { Fahr. } \\
96^{\circ}\end{array}$ & $\begin{array}{l}\text { Fahr. } \\
-10 \cdot 5^{\circ}\end{array}$ & $\begin{array}{c}\text { Fahr. } \\
14^{\circ}\end{array}$ & $\begin{array}{l}\text { Fahr. } \\
-2 \cdot 2^{\circ}\end{array}$ \\
\hline $\begin{array}{l}\text { Latent Heat } \\
\text { of vapori } \\
\text { at atm. pr }\end{array}$ & $\left.\begin{array}{l}\text { ation } \\
\text { ssure }\end{array}\right\}$ & 966 & 900 & 165 & 473 & 182 & - \\
\hline See Fig. 1, & Fahr. & Lbs. & Lbs. & Lbs. & Lbs. & Lbs. & Lbs. \\
\hline Plate 52. & $-40^{\circ}$ & - & - & - & - & - & - \\
\hline A ho & $-20^{\circ}$ & - & $19 \cdot 4$ & - & $12 \cdot 0$ & $5 \cdot 7$ & $11 \cdot 6$ \\
\hline & $0^{\circ}$ & - & $30 \cdot 0$ & $1 \cdot 5$ & $18 \cdot 7$ & $9 \cdot 8$ & $15 \cdot 4$ \\
\hline rapour & $+20^{\circ}$ & - & $47 \cdot 7$ & $2 \cdot 6$ & $28 \cdot 1$ & $16 \cdot 9$ & $22 \cdot 0$ \\
\hline 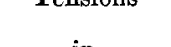 & $+32^{\circ}$ & 0.089 & $61 \cdot 5$ & $3 \cdot 6$ & $36 \cdot 0$ & $22 \cdot 7$ & $27 \cdot 0$ \\
\hline 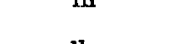 & $+40^{\circ}$ & $0 \cdot 122$ & $73 \cdot 0$ & $4 \cdot 5$ & $42 \cdot 5$ & $27 \cdot 3$ & $31 \cdot 3$ \\
\hline & $+60^{\circ}$ & 0.254 & $108 \cdot 0$ & $7 \cdot 2$ & $61 \cdot 0$ & $41 \cdot 4$ & $44 \cdot 0$ \\
\hline per & $+80^{\circ}$ & 0.503 & $152 \cdot 4$ & $10 \cdot 9$ & $86 \cdot 1$ & $60 \cdot 2$ & $60 \cdot 0$ \\
\hline Dqualo & $100^{\circ}$ & 0.942 & $210 \cdot 6$ & $16 \cdot 2$ & $118 \cdot 0$ & $84 \cdot 5$ & $79 \cdot 1$ \\
\hline & $120^{\circ}$ & $1 \cdot 685$ & $283 \cdot 7$ & $23 \cdot 5$ & - & $117 \cdot 5$ & $99 \cdot 7$ \\
\hline du & $140^{\circ}$ & $2 \cdot 879$ & - & $33 \cdot 5$ & - & - & - \\
\hline Winesen & $160^{\circ}$ & $4 \cdot 731$ & - & $45 \cdot 6$ & 一 & - & - \\
\hline & $180^{\circ}$ & $7 \cdot 511$ & - & $62 \cdot 0$ & - & 一 & - \\
\hline & $200^{\circ}$ & $11 \cdot 526$ & - & $81 \cdot 8$ & - & - & - \\
\hline & $212^{\circ}$ & $14 \cdot 7$ & - & $96 \cdot 0$ & - & - & - \\
\hline
\end{tabular}




\section{Discussion.}

Mr. Lrantroot exhibited an excellent working model, made by Messrs. Siebe Gorman and Co., which represented one of the vertical cold-air machines shown in Figs. 22 and 23, Plate 61, and was about one-quarter full size, a chamber being attached for illustrating its action. The air was either drawn back from the chamber by the suction-pipe of the machine, in order to be used over again, or was allowed to escape direct into the atmosphere.

A late typo of the Haslam dry-air refrigerator, shown in Figs. 12 and 13, Plate 56, really consisted of two complete refrigerating machines, placed side by side on one large bedplate, and capable of being worked either independently or together. When the whole apparatus was in operation, the steam was used expansively on the compound principle, expanding from the small into the large steam cylinder; but in case of accident either side might be worked alone, with high-pressure steam. If necessary the main shaft might be disconnected at the point $\mathrm{X}$, Fig. 13 .

Colonel B. H. Martrndale, C.B., R.E., agid that, as the general manager of the London and St. Katharine Dock Company, he had been connected for the last five years with the practical working of arrangements for preserving refrigerated meat from the colonies on perhaps the largest scale that had ever been carried out in England. In 1881 the dock company were pressed by some of their Australian friends to make arrangements for receiving frozen meat and storing and distributing it. They began necessarily on a very small scale. Happening to have under one of their warehouses a large vault about 500 feet long, divided longitudinally into four arches each 16 feet wide, they made use of part of it for their storage. They began with a small engine obtained from Messrs. Hall of Dartford, delivering 10,000 cubic feet of cold air per hour; and that engine did good work until 1884, when it was removed to make room for a larger one. They gradually increased the number of their 
cold storage chambers, until they had now got fifty-six chambers in two vaults. The smallest chamber had a cubic content of 2,273 feet, and the largest of 9,280 feet, the total content of the fifty-six chambers being something over 183,000 cubic feet. It was found that the carcasses averaged in weight 56,60, and $72 \mathrm{lbs}$; and if the chambers could be completely filled they would hold about 59,000 sheep of the first weight, 56,000 of the second, and 44,000 of the third. But in practice a space had to be left for gangways, and for separating different marks, especially in consignments from New Zealand; and a proportionate deduction had therefore to be made from what could otherwise be stored. Still the chambers could always store about 44,000 sheep, taking the shipments as they chanced to arrive.

The construction of the chambers had varied a little in detail, and was somewhat different from what had been described in the paper. The last chambers that had been built had been constructed according to the recommendation of Mr. Haslam of Derby. On the original concrete floor of the vault there was placed a longitudinal layer of $1 \frac{1}{4}$-inch rough boards, on which were laid transverse bearers, $4 \frac{1}{2}$ inches deep by 3 inches wide and 21 inches apart. On these bearers was laid a $2 \frac{1}{2}$-inch batten floor, grooved and tongued. The sides and roof were constructed with $5_{2}^{\frac{1}{2}} \times 3$-inch uprights, fixed on the floor bearers. On these uprights there was an outer skin of 2-inch boards; and an inner skin formed by two thicknesses of 11-inch boards, between which was a thickness of specially prepared brown paper. The $5 \frac{1}{2}$-inch space between the inner and outer skins of the sides and roof, and the $4 \frac{1}{2}$-inch space between the floor and rough boards, were filled with carefully dried wood-charcoal. All the boards were finished to a uniform thickness, and were grooved and tongued. Cold air was conveyed by wooden trunks from the refrigerating machines into the chambers, entering them at one end close to the roof, and being drawn off at the other end, also close to the roof, by return air-trunks leading back to the refrigerating machines. From the quantity of snow made by the engines, the air-trunks had to be cleared out every twenty-four hours, and the engine snow-boxes about every four hours. All sharp rises or falls 
(Col. B. H. Martindale, C.B., R.E.)

in the air-trunks should be aroided by conducting the air through sloping trunks. In a properly insulated air-chamber, flled with frozen carcasses and kept closed, the temperature should not rise more than about $6^{\circ}$ in twenty-four hours if the engines were stopped for that length of time. In order to make some use of the snow, which in any case was an exceedingly objectionable product, it was thrown into boxes fixed over a drain, and through these boxes passed the pipe conveying the circulating water.

At present they had four of Haslam's 60,000 cubic feet machines, and three of Hall's 30,000 cubic feet machines. These were supplied with steam from three multitubular boilers of the marine type, and four boilers of the locomotive type. If they started afresh, they would not have any boilers of the locomotive type; but they had had to feel their way step by step with the gradual growth of the trade.

At the stores at the A jetty, one of Hasham's 60,000 cubic feet machines was working at the present time on fifteen chambers, having a total capacity of 48,000 cubic feet, which were capable of storing 11,000 sheep of an average weight of $72 \mathrm{lbs}$; ; but allowing for gangways and for divisions of marks, that number had to be reduced to 8,000 or 9,000 . The engine was running twenty hours out of every twenty-four. The four hours' stoppage included the necessary time for clearing valves, snow-boxes, and air-trunks. The average speed was 80 revolutions per minute at an air-pressure of 44 lbs. per square inch, giving a temperature of $-57^{\circ}$ in the snow-boxes, and keeping the chambers down to a temperature of from $15^{\circ}$ to $18^{\circ} \mathrm{Fahr}$, which was found in practice to be about the best temperature to keep the meat at. It had been found that better results were obtained in proportion to fuel by working at an air-pressure of about $44 \mathrm{lbs}$. per square inch, instead of 50 lbs. and upwards : not giving such a low temperature in the snow-boxes, but about $-50^{\circ} \mathrm{Fahr}$. instead of $-60^{\circ}$ or $-70^{\circ}$, and delivering a larger volume of cold air into the chambers; the proportionate rise in temperature was then much less between the delivery from the expansion cylinder and the distant chambers. At the same jetty węre two of Hall's 30,000 cubic. feet machines, working on fifteen chambers of about the same capacity, 
and doing just about the same work. The coal used in the twenty hours was about $4 \frac{1}{2}$ tons for the three machines together.

At the B jetty, two of Haslam's 60,000 cubic feet machines were working on twenty-four chambers of 90,000 cubic feet capacity, running at an average of 70 revolutions per minute with an airpressure of $40 \mathrm{lbs}$. per square inch, a temperature of $-55^{\circ}$ in the snow-box, and a coal consumption of $4 \frac{1}{2}$ tons in the twenty hours. That was much the same result as with the 60,000 and the two 30,000 cubic feet machines at the $A$ jetty.

The rise of temperature in the air in travelling to the chambers at any distance was generally considerable. As a rule the chamber next to the engine was kept at a sufficiently low temperature with but little opening of the delivery ports in the air-trunks, and almost without admitting air at all; the mere passage of the air-trunks through it kept it almost cool enough. The greatest care had to be taken in regulating the delivery and return air-ports, gradually increasing the area of both in proportion to the increased distance. The greatest distance that the air was conveyed was 180 feet. The practical result of the observations taken, extending over some time, was that the rise of temperature in travelling was $1^{\circ} \mathrm{Fahr}$. for every 18 or 20 feet travelled; but this must not be taken for more than the result arrived at from general working under existing conditions.

The consumption of $4 \frac{1}{2}$ tons of coal in twenty hours for the three engines at the $A$ jetty together, giving out nominally 120,000 cubic feet of air per hour, was equivalent to $1 \mathrm{lb}$. of coal for every 240 cubic feet of cold air delivered. The coal used was ordinary Welsh coal at about $16 s$. $6 d$. per ton.

It had also been found that from 1 to $1 \frac{1}{2}$ cubic foot of cold air per hour would keep cool-say at $18^{\circ} \mathrm{Fahr}$. -1 cubic foot of storage at a distance not exceeding 180 feet, or say at an average distance of 90 feet. The result which he had first arrived at had been that in temperate weather 1 cubic foot of cold air per hour was sufficient to keep cool 1 eubic foot of storage. Some considerable time after he had arrived at that conclusion he mentioned it to Mr. Haslam, and to his pleasure found that he also had arrived at the same 
(Col. B. H. Martindale, C.B., R.E.)

conclusion. But allowance had to be made for openings of doors for the purpose of deliveries and so on; and on this account he thought the quantity of air required could not be put at much under $1 \frac{1}{2}$ cubic foot per hour for every cubic foot of storage that was wished to be kept down to say $18^{\circ} \mathrm{Fahr}$. Of course if the chambers were to remain undisturbed and fully stored with carcasses, one cubic foot of cold air for every foot of storage would probably be found sufficient.

One precaution to be observed in connection with all apparatus employed for refrigerating meat was that, if chemicals were used in producing the cold, it was an absolute necessity that the air delivered should not have the faintest trace or smell of them. No consignee would keep his meat in any store where he could detect the slightest taint of that kind.

Mr. Frederick Colyer, regretting that he was prevented by illness from being present, sent the following remarks upon the paper, which were read by direction of the President:-

"The paper forms a valuable contribution to the Proceedings, especially as the author has had so much experience in this class of machinery.

"On page 211 Harrison's ether machine is mentioned as being the first ice-making machine that came into practical use in this country. It may be of interest to state that one of the first of Harrison's machines made on this system is still at work at Messrs. Truman Hanbury and Co.'s browery, and is acting very efficiently; it has been there I believe about thirty years.

"On page 212, where the quantity of cooling water used in the condenser is given as 150 gallons per hour for each ton of ice made per twenty-four hours, I should like to know the temperature of the water at the inlet of the condenser, as this makes a material difference.

"On pages 215 and 230 the consumption of coal per indicated horse-power is taken at 2 lbs. per hour. This $I$ think is too low an estimate, and that. 3 to $4 \mathrm{lbs}$. would be nearer. The price of coal also, which is taken by the author at $15 s$. per ton, is too low, at any 
rate in the London district; it should be $18 s$. to $20 \mathrm{~s}$. These corrections would raise the cost per ton for producing block ice.

"On page 231 English beer is spoken of as not being cooled below $50^{\circ}$ Fahr. This is really much lower than is usually the case; $60^{\circ}$ would be nearer as a rule.

"On page 232, I quite agree with the author that cold-air machines would be the most suitable for cooling rooms for fermenting and other purposes; but the cost of fuel stands in the way at present.

"Machines for cooling water and making ice may be divided into two classes:- one in which ether is used, and the other in which ammonia is the medium. The other systems mentioned in the paper are seldom employed in this country.

"With ether machines there are adrantages which in some instances may decide their use when space is limited or when the machine has to be placed in underground rooms; those made upon the horizontal plan can often be adopted where it would be almost impossible to use the ammonia machine.

"In London, where coal is dear and water has often to be obtained from the water companies, the ether system is more expensive than the ammonia; added to which a much larger quantity of condensing water is required; and, taking into consideration the high temperature the water often attains in the street mains during summer, the increased quantity used by the ether machine is a serious matter.

"The ammonia machines-whether those described on page 219, such as the Pontifex-Reece system, or those worked on the compressed plan-are as a rule far more economical in working than any ether machine. They should however be adopted only where the plant can be partly open to the air; it is almost impossible to prevent a slight leakage, which in many instances would preclude their use, as the vapour given off would be injurious to other processes carried on at many establishments.

" Having tested the working of some of the leading ether machines, and also of the Pontifex-Reece ammonia machine, I have obtained the following results, which may be of interest. 
(Mr. Frederick Colyer.)

"In an ether machine made by Messrs. Siebe Gorman and Co., capable of cooling 3,200 gallons of water from $60^{\circ}$ down to $50^{\circ}$ or abstracting 320,000 heat-units per hour, the average of experiments gave 4,250 gallons per hour cooled $10^{\circ} \mathrm{Fahr}$. The temperature of the water at the inlet was $54^{\circ}$, and that of the water used for condensing purposes was the same. The maximum cooling effected was 449,437 heat-units abstracted per hour, being from 35 to 40 per cent. above the nominal power of the machine. The condensing water used per hour was 1,262 gallons, or about 3-10ths of a gallon for every gallon of water cooled. The coal consumed was ' $3 \frac{1}{4} \mathrm{cwts}$. per hour; it was of indifferent quality, or the consumption would have been smaller. The steam cylinder was 21 ins. diameter and 27 ins. stroke; the air-pump 24 ins. diameter and 27 ins. stroke. The speed of the engine was 58 revs. per minute, with 48 lbs. steam cut off at one-third of the stroke. The indicated power of the engine was $53 \mathrm{HP}$., and of the air-pump $29 \cdot 2 \mathrm{HP}$. The boiler was $7 \mathrm{ft}$. diameter and $24 \mathrm{ft}$. long, and gave an ample supply of steam. This is the most efficient ether machine that has come under my notice, and contains several improvements not usually found in others of the same class.

“In a Pontifex-Reece ammonia machine, capable of cooling 5,500 gallons of water per hour through $10^{\circ} \mathrm{Fahr}$., 6,388 gallons per hour were actually cooled $10^{\circ}$, being about 16 per cent. above the nominal power. The condensing water used per hour was 1,320 gallons at $45 \frac{1}{2}^{\circ}$. The fuel consumption in twenty-four hours was $21 \frac{1}{2} \mathrm{cwts}$. of the very common coal in the Glasgow district, or $100 \mathrm{lbs}$. per hour. The steam pressure was 50 lbs. per square inch ; the boiler was $6 \mathrm{ft}$. diameter and $20 \mathrm{ft}$. long.

"The same Pontifex-Reece ammonia machine when employed for making ice is capable of producing 15 tons in twenty-four hours if worked with three boxes, or 10 tons with two boxes. In the experiment two boxes only were used. The coal consumption was $25 \frac{1}{4} \mathrm{cwts}$. in twenty-four hours, or 120 lbs. per hour, or $192 \mathrm{lbs}$. of coal per ton of ice. Including all expenses, wear and tear, interest and sinking fund, the cost of the ice was $4 s$. per ton. The condensing water used, having a temperature of $46^{\circ}$ at the inlet, was 1,154 
gallons per hour; and 1,340 gallons in full working with three boxes. The engine was 6 HP. nominal. The boiler pressure was $43 \mathrm{lbs}$. per square inch, and the boiler used was the same as in the cooling experiment.

"In ammonia machines worked upon the compressed system the difficulty has hitherto been to keep the working parts tight at the joints. I believe Messrs. Siebe Gorman and Co. are about to bring out a machine that will be free from this difficulty. From my own experience with cooling and ice-making machines I am led to think that the ammonia system will shortly be the only one used upon any extensive scale.

"As to the amount of ice produced per ton of coal in Pictet's process, mentioned in page 223 of the paper, I think it is overstated at 35 tons. Half that production would still be very high.

"With cold-air machines the author has had as much experience as any one, and $I$ have therefore been hoping to learn what he could do towards producing a machine capable of cooling air economically in a large room, not a sealed chamber. In breweries and other places, such a machine would be a great boon; hitherto the machines tried have been little more than costly failures. The difficulties are very great, it is true; but much has been done by the author in this direction, and $\mathrm{I}$ am looking forward to a successful solution of the problem. No other machine than his I think would be of any practical service for this purpose. The cost, as well as want of efficiency, has always stood in the way of the practical use of cold-air machines for cooling large rooms."

Mr. W. A. Gonman mentioned that the ether machine, referred to by Mr. Colyer as still at work at Mossrs. Truman's brewery, had been made by the late Mr. Siebe, and was the first machine made on Mr. Harrison's plan except the one taken by himself to Australia. For a small production of from $2 \mathrm{cwts}$. up to 3 tons of ice per day, the ether machine was much liked on account of the low working pressure in the condenser, not exceeding $10 \mathrm{lbs}$. per square inch even in India. In one instance a half-ton machine of this kind was driven in conjunction with dynamo machines by water power. 
(Mr. W. A. Gorman.)

The working model exhibited of a vertical cold-air machine he should have had much pleasure in presenting to the Institution, if they had had a suitable place in which to keep such models, as he hoped would at some future time be the case.

Mr. JaMes HaRRIson drew attention to the figures given for the latent heat of vaporisation in Table 2, where that of ammonia was set down at 900 and that of sulphuric ether at 165 . No doubt these were the correct figures for equal woights of the substances at atmospheric pressure. But the ice-maker, using pumps which were measures not of weight but of capacity, did not deal with vapours by weight but by volume; and did not work at atmospheric pressure. At pressures below the atmosphere the latent heat of vaporisation was increased, and at pressures above the atmosphere it was diminished. On making these corrections it would be found that at $32^{\circ}$ Fahr., and with a vacuum of $11 \cdot 1$ lbs. per square inch below the atmosphere, the latent heat of ether in the ice-making process was 656 instead of 165 ; and in working with ammonia at $32^{\circ}$, and at a pressure of $46.8 \mathrm{lbs}$. above the atmosphere, its latent heat was reduced from 900 down to 845 . Other considerations connected with the temperature of condensation of the vapours of ammonia and ethor led him to the conclusion that these two refrigerating agents were nearly equal in efficiency. Indeed it was his opinion that of all the different refrigerating agents of this class there was no one really better than another, but that all were about equal; and that if in any process one seemed to be more efficient than another, it was simply because the arrangements for its use had been better carried out in respect of that process. It so happened that in his first Australian design he had planned a process of ice-making by ammonia, which combined both the compression and the absorption processes before either of these had been invented separately. But he had not proceeded with the use of ammonia as a refrigerator, having subsequently given the preference to ether.

Mr. R. Priog-Williams should have been very glad of more particulars as to the cost of different processes per ton of ice made, which 
according to the paper appeared to vary from $9 s .3 d$. on page 204 to $3 s$. $9 d$. on page 218 , while it was stated on page 221 that the average cost by the absorption system might be taken at 48 . In a recent voyage to Australia he had had an opportunity of examining very carefully the refrigerating process referred to in page 235 as having been carried out by $\mathrm{Mr}$. Manuel, and could bear willing testimony to the admirable way in which it served its purpose. In Australia the use of refrigerating machinery for the preservation of meat was already becoming a subject of great importance; and there was no disguising the fact that in this country it was a very important one indeed. So much so that Sir William Armstrong, in a letter to himself, dealing with the very rapid increase of population in this country, admitted it to be one of the gravest questions of the day; and pointed out very forcibly what a terrible thing it would be for this country if it should ever happen that the freedom of navigation should be destroyed, considering that we were absolutely dependent upon food supplies from abroad. By means of this refrigerating process, any amount of food that could be taken by this country could now be sent over from Australia. But he had been given to understand that a mistake had been made in freezing the meat for transport, and that the arrangements must be such that the meat should not be absolutely frozen, but should be kept down as near the freezing point as possible. Mr. Manuel's arrangement he had noticed was so contrived that nothing was actually frozen; and the butter and meat were as fresh at the time of arriving at King George Sound in Western Australia as on the day of leaving England. The valuable information afforded by Colonel Martindale's remarks was not only highly interesting to those who had listened to them, but would also be of very great interest on the other side of the world.

In connection with the successful application of the refrigerating process on board ships, it had struck him that it might be equally and with very great advantage applied to the berths, in which, under the heat of the tropies and with port-holes closed for many days, a temperature above $100^{\circ}$ Fahr. had to be endured. From an estimate made during the royage in the Massilia, he came to the conclusion that by the expenditure of the small sum of $\$ 700$ on board that fine 
(Mr. R. Price-Williams.)

vessel the berths might be maintained at a constant temperature of from $60^{\circ}$ to $70^{\circ} \mathrm{Fahr}$. if desired. The adoption of this suggestion by the Peninsular and Oriental Company would add very largely to the comfort of their passengers, and he believed would induce people to make journeys to the torrid zone much more frequently.

Great credit he thought was due to the author for the admirable way in which he had placed this subject before the Institution. It was evident that he had devoted a large amount of time to it, and had made it his special study.

In regard to the very interesting means of arresting the running ground for putting the Stockholm tunnel in, he enquired whether the setting of the mortar was not interfered with; because it was well known that if brickwork were laid during frost it was apt to blow, and masons never set brickwork, or anything with mortar, during frost if they could avoid it. He should have feared the freezing of the ground in the manner described in the paper would have very much interfered with the proper setting of the mortar.

Mr. Druitt HaLPIN observed it was pointed out in page 233 of the paper that, when once the chamber and its contents were cooled down to the required temperature, all that the refrigerating machine had then to do was to overcome the leakage of heat passing in through the walls. If that could be prevented, of course theoretically the machine could be stopped altogether. The importance of the insulation was therefore very great, because a large amount of power and coal was being used to neutralise the leakage. The best non-conductor of heat, as was well known, was air ; and the more air was entangled, the more efficient it became. In Germany he had lately made some experiments, extending over a week, with cork as a non-conductor, according to a plan now in use there. In France cork had been used many years before, and had been employed in the 1878 Exhibition, where it answered efficiently for protecting steam pipes; but the objection in the French arrangement, as far as he understood, was the expense. Ordinary cork was cut up into slices, and a good effect was thereby obtained, but at very great expense. In Germany however all the refuse and waste cork was used; it was ground up 
into powder, and was then cemented together again, and made an exceedingly cheap non-conducting material. The broad results of his own tests with this cork were that from 92 to 93 per cent. of the transfer of heat was totally arrested, and only 7 or 8 per cent. of heat passed through.

Mr. WILliam SchönheXder remarked that in the tunnel at Stockholm it appeared the cold air had simply been delivered by means of a shoot into the working chamber, and there allowed to take care of itself, Of course it picked up heat from the surrounding ground, and the warmer air would rise to the ceiling, and there stop, unless it were taken away. If a higher temperature were really wanted near the ceiling, so much the better; but if it were wanted to have the air cold near the ceiling, the plan would have been either to withdraw the air from the ceiling by means of a powerful pump, or simply to insert a curved tube from the outside, terminating near the ceiling, so that, while the cold air was blown into the chamber by the machine, the warmer air might be continually taken away from near the top by the tube. In the cold storago arrangement shown in Fig. 26, Plate 62, the cold air was admitted near the ceiling and the warm air was taken away from near the ceiling. Perhaps that did not matter very much, because directly the cold air came in it would fall to the floor, and as it picked up heat from the surrounding walls, it would rise and go out at the top; so far that was right enough. But if with these cold-air machines there was any chance of snow getting in with the air and collecting in the chambers, it seemed to him that in this arrangement where it was admitted near the ceiling it had a great opportunity of falling upon the meat, and possibly deteriorating it. The air might just as well be admitted near the floor, which was the proper place for it to enter at. It would then gradually rise as it picked up heat from the chamber and its contents; and it should be taken away from near the ceiling, as was already done.

Mr. Thomas Powel, Rouen, being unable to come to the Meeting and take part in the discussion, sent the following observations 
(Mr. Thomas Powell.)

resulting from his own experience with Windhausen's vacuum plan :-

"The importance of refrigerating and ice-making machinery is constantly increasing, and the artificial production of cold is becoming more and more extensively useful in various manufactures. Being myself engaged in the manufacture for France and her colonies of vacuum machines on Windhausen's plan, which in England has been but little nsed, I am able to offer some supplementary information regarding it, beyoud that given in the paper. The remarks there made would fairly have applied to this plan two years ago; but since then improvements have been made, whereby all the objections that attended it have been thoroughly met.

"The first of these improvements has reference to the quality of the ice. Instead of the water to be frozen being subjected direct to the vacuum itself, the vacuum is made to act upon a liquid that will not freeze at the lowest temperature employed in the apparatus. A solution is used of chloride of sodium or magnesium or calcium, which in its partial vaporisation loses heat enough to bring its temperature down to $14^{\circ}$ or even to zero Fahr. $\left(10^{\circ}\right.$ or $18^{\circ}$ below zero Cent.). Under the action of a pump, the cold liquid circulates continuonsly between the evaporator or refrigerator in which the cold is produced, and the apparatus or place where the cold is to be utilised. It is thus both the means by which the cold is produced, and also the carrier by which it is transmitted. It can be conveyed either into tubular coolers, such as are used in breweries, or into any other apparatus where the cold is wanted to be utilised; and in icemaking apparatus the ice thereby produced is either opaque or transparent according to the nature of the apparatus employed, just as in the case of all other plans for making ice. By means of the processes already known, the ice can on this plan be made perfectly transparent, and in blocks of any forms and sizes. In my own works I am at present trying a very simple apparatus for producing transparent ice without stirring the water at all, and without using distilled water. The method consists simply in gradually increasing the coldness of the liquid used for freezing the water. 
"Another improvement made more than a year ago in our machines consists in causing the sulphuric acid to circulate continuously under the action of a pump between the absorber, in which it becomes diluted through the work that it does there, and the concentrator, in which it is regenerated. Formerly work had to be stopped every six or seven hours for an hour at least, in order that the weak acid in the absorber might be replaced by a fresh charge of strong acid. By the improved arrangement the machine can now work continuously without interruption, except for such attention as all running machinery requires. An increased production is thus obtained of at least 15 per cent., accompanied by a decided saving in power, inasmuch as it is from the moment of starting the vacuum pump until the full amount of vacuum is produced that the greatest power is required.

"Another consequence resulting from the continuous circulation of the acid is that the machine works much more regularly, the production of cold is uniform, and risk of damage in the various parts of the apparatus, particularly in the concentrator, is almost entirely got rid of. The concentrator itself, which in the old machines was certainly deficient in strength and has undoubtedly been the cause of this plan not having come more into use, has been entirely altered, or replaced by various other modes of construction, which have all of them given very satisfactory results. One of these new concentrators, designed in London, is now under trial. An entirely difforent one has already undergone a number of trials in Berlin; and a third is employed in my works, where it is giving complete satisfaction.

"In regard to cost of working, the production of cold by vacuum with the aid of sulphuric acid shares with ammonia absorption the advantage rightly pointed out in the paper, namely that in these two plans the heat necessary for performing the work is for the most part applied direct, without being transformed into mechanical power. In our system the heat is employed in regenerating the acid by concontration; the power expended in driving the vacuum pump forms only a small portion of the total work. 
(Mr. Thomas Powell.)

"Although not for the production of cold, another application of this plan of machine may be mentioned, which is nevertheless of high importance, namely for evaporating and drying in a vacuum and at a low temperature:- for instance, evaporating the syrups of sugar and starch ; concentrating fruit syrups for preserving, without their being at all injured by heat; concentrating grape-must for carriage, and preserving it without fermentation; condensing milk; thoroughly drying meat and glue, \&c. The plan is suitable in fact for all kinds of substances, which in the ordinary process of concentration by heat and under atmospheric pressure suffer more or less deterioration. By this means milk can be frozen solid without. reducing its temperature lower than $4^{\circ}$ below zero Fahr. $\left(20^{\circ}\right.$ below zero Cent.), and consequently without coagulating the albumen; this is done by simply putting the vessel containing the milk into communication with the vacuum apparatus. The importance of such a result can hardly fail to be appreciated."

Mr. Lightroot, in reply, observed that Colonel Martindale had furnished a large mass of information in regard to the working of cold-air machinery and storage chambers, which if accurate would be extremely useful. He had no particular reason for doubting its accuracy, as far as the dock company was concerned; but he had found in many instances that refrigerating machines, sold to give a certain delivery of cold air per hour, fell far short of that delivery in practice; therefore, unless the capacities were arrived at from the actual sizes of the cylinders and conditions of working, he feared it would be unsafe to draw any deductions, or to make comparisons between the volume of air delivered and the space cooled. Not very long ago a case had come under his notice in which the capacity of the machine, stated as so many thousand cubic feet of cold air per hour, had actually been calculated from the capacity of the compressor, a method which gave a delivery nearly double of that obtained in practice.

That there was something wrong in the figures seemed to be shown by the coal consumption, which was given as $4 \frac{1}{2}$ tons per twenty hours for three machines stated as delivering collectively 
120,000 cubic feet of cold air per hour. As at least 220 indicated horse-power would be required to give this production of air, the coal consumption was equivalent to $2 \frac{1}{4} \mathrm{lbs}$. per indicated horse-power per hour, a result which he considered could not possibly be obtained with the not very efficient boilers and engines in use at the docks, the engines being of a type that would entail a fuel consumption at least one and a half times as much as that required to develop the same result in his horizontal machine with compound condensing engine, as shown in Figs. 17 and 18, Plates 58 and 59. He therefore felt quite sure that, if the coal consumption had been correctly given, the air delivery could not be taken at anything like 120,000 cubic feet per hour; and if this was so, the whole of the calculations and deductions therefrom were upset.

With regard to Mr. Colyer's remarks, the water consumption for the ether machine was merely given as a general guide, the amounts actually used varying too much to permit of any accurate statement being made. The consumption and price of coal were not put forward as being the actual figures in any particular case, but had been assumed as a basis of calculation common to all the machines; they would therefore have to be altered according to circumstances. At the same time the most improved class of cooling and ice-making machinery was now made with engines developing one indicated horse-power with about 2 lbs. of coal per hour. He could not understand why the ether machine could be used in situations where an ammonia machine could not be got in. If an ammonia absorption apparatus was referred to, it might be true; but an ammonia compression machine occupied less space than any machine with which he was aquainted. He had not stated as a definite fact that Pictet's new process produced 35 tons of ice per ton of coal; but there was nothing impossible in such a result. Probably actual figures would be made known before long, and it would then be time enough to come to a definite conclusion. He was afraid he could hold out no hope that cold-air machines would ever be capable of being economically applied for cooling air in large rooms, such as were to be found in breweries; nor indeed did he see why such an application was to be desired, as there was no difficulty whatever in 
(Mr. Lightfoot.)

cooling by means of brine from an ammonia or other machine-a system that had been very extensively adopted, and found to work well.

It had been correctly pointed out by Mr. Harrison that the heat. of vaporisation varied with the pressure at which evaporation occurred; this was well known, and had been referred to in the paper. Unfortunately the latent heats of vaporisation at different pressures had never been determined for the liquids used by the ice-maker, except in the case of water; and therefore all that could be done was to give those at ordinary atmospheric pressure. In determining the proper size of pump to produce any given effect, it was necessary to take into account the specific gravity of the vapour as well as the heat of vaporisation at the particular pressure at which it was intended to work the apparatus.

The cost of ice-making had been estimated upon the same bases for all the different machines; and he was afraid he could not furnish more detailed information, as suggested by Mr. Price-Williams. In point of fact each particular case required special consideration; and all that could be attempted in a paper such as the present was to give general results with machines of the same capacity and worked under similar conditions, which might be used for comparing the efficiencies of the various systems. Other matters however, besides mechanical and thermal efficiencies, had frequently to be considered. In reference to the question of freezing the meat brought over to this country, he believed it was essential that it should be frozen if it was to be preserved for more than from two to three weeks; for even if the temperature was maintained as low as $35^{\circ}$ Fahr., a slow process of decomposition or a slow chemical change would take place, which if continued beyond that time rendered the meat tasteless, and otherwise lowered its quality. On the other hand he believed that no chemical change took place when the meat was frozen. There was a slight mechanical change, and the cellular tissue was to some extent destroyed; consequently when thawed there was a tendency for the juices to escape. This however was got over by hanging the carcasses and joints so that the juices were retained. His experience was that on board the Peninsular and. 
Oriental Company's steamers the meat was frozen; the length of voyage necessitated it.

No trouble had arisen from a deposit of snow upon the meat. As a matter of fact with his machines snow never got into the storago chamber; but if it did, no harm would ensue, so long as the meat was frozen. Various means had been tried for admitting the cold air; but the general practice now was to let it in by means of a duct near the ceiling, and draw it away by another duct also at the ceiling, but remored as far as possible from the inlet.

No difficulty had been experienced in setting the cement in the Stockholm tunnel. The arch was constructed after the partition forming the freezing chamber was removed; and although the gravel next the cement was frozen, no ill effects had been felt. In regard to the method of applying the cold air in the freezing chamber, it must be borne in mind that, as mentioned in the paper, it had been considered advantageous that the gravel at the top of the tunnel should not be frozen. Had it been desirable to freeze at this part, means would have been devised for doing so.

Respecting the use of cork as a non-conductor, he should be glad of some particulars as to the experiments referred to by Mr. Halpin, because the mere statement of the percentage of heat passing through was hardly sufficient. These matters were generally dealt with by stating the transmission of heat in thermal units through one inch thickness of the material, per square foot, per hour, per degree of difference in temperature; and if the results with cork could be given in that form, it would be an advantage. The question of insulation was a very important one, and he had himself experimented with most of the substances generally used. In several cases he had employed silicate cotton, which for some purposes was better than almost anything else. But charcoal he believed was the best insulator for general use.

He could not consider that all the objections to the Windhausen vacuum process had been met by Mr. Powell. No doubt improvements had been effected since the machine was erceted at Lillie Road, the principal change being in the elimination of defects in the concentrator, and in rendering the working of the plant continuous. 
(Mr. Lightfoot.)

The method of producing clear ice had already been referred to in the paper, and was well known to those acquainted with ice-making plant. It could only however be taken as an improvement, in so far as it enabled clear ice to be made : against which would have to be set an increase in the amount of fuel consumed per ton of ice, as well as an increase in cost of labour. The vacuum process he feared could never compete with ammonia as regarded cost of production, while there could be no doubt that the plant was more costly to maintain and manage.

Mr. W. Silver Hall suggested that the question about the seting of the brickwork in the Stockholm tunnel was almost answered by the diagram itself, Fig. 32, Plate 63, which showed that the brickwork was put in outside the freezing chamber.

The President asked the members to pass a hearty vote of thanks to Mr. Lightfoot for his very interesting and instructive paper; and he thought they might fairly include in the vote of thanks those who had contributed to the discussion, especially Colonel Martindale, Mr. Colyer, and Mr. Powell, who had given very valuable information on the subject dealt with. 
REFRIGERATING MACHINERY. Plate 52.

Fig. 1. Curves of Vapour Tersions.

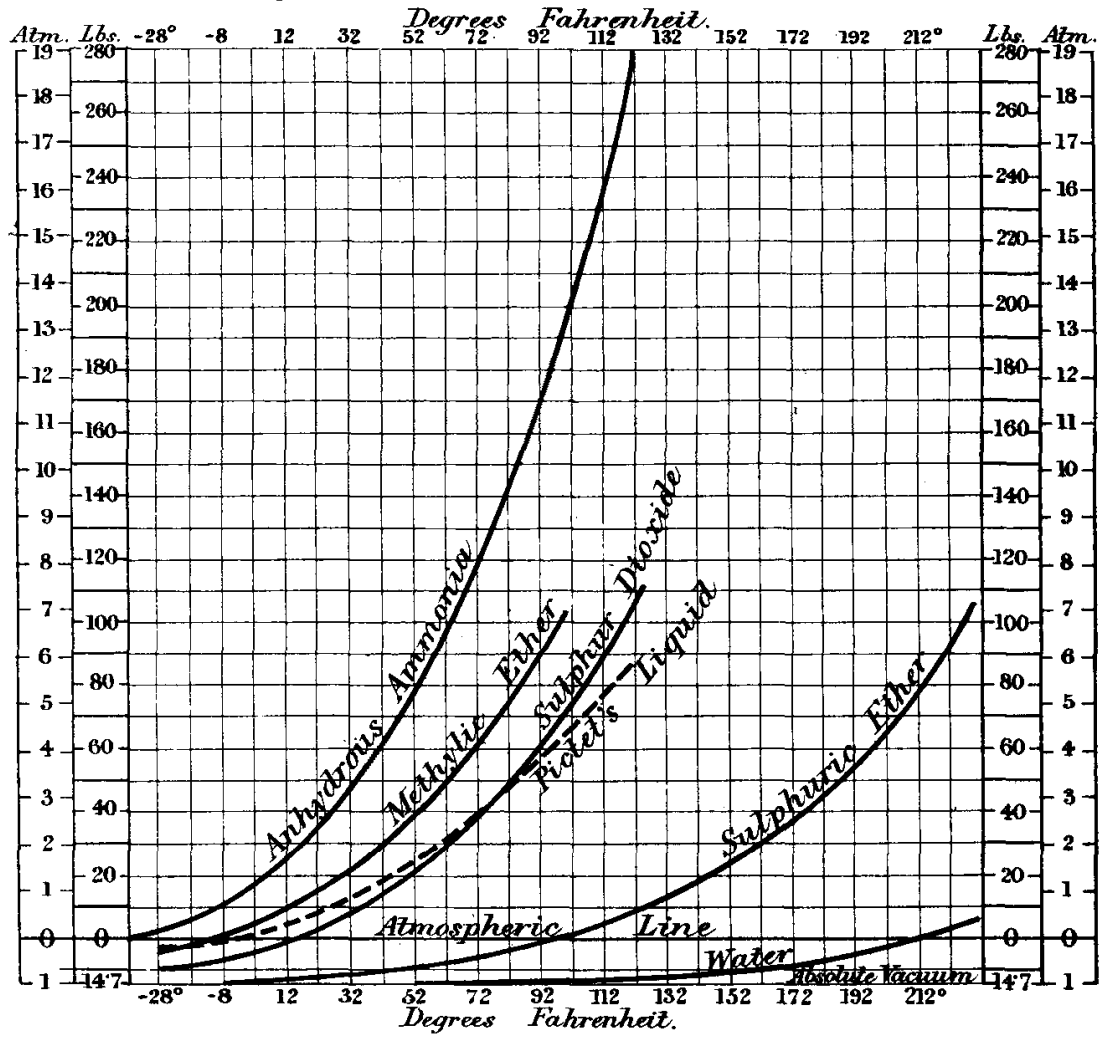

Fig. 2. Compression and Expansion of Air.

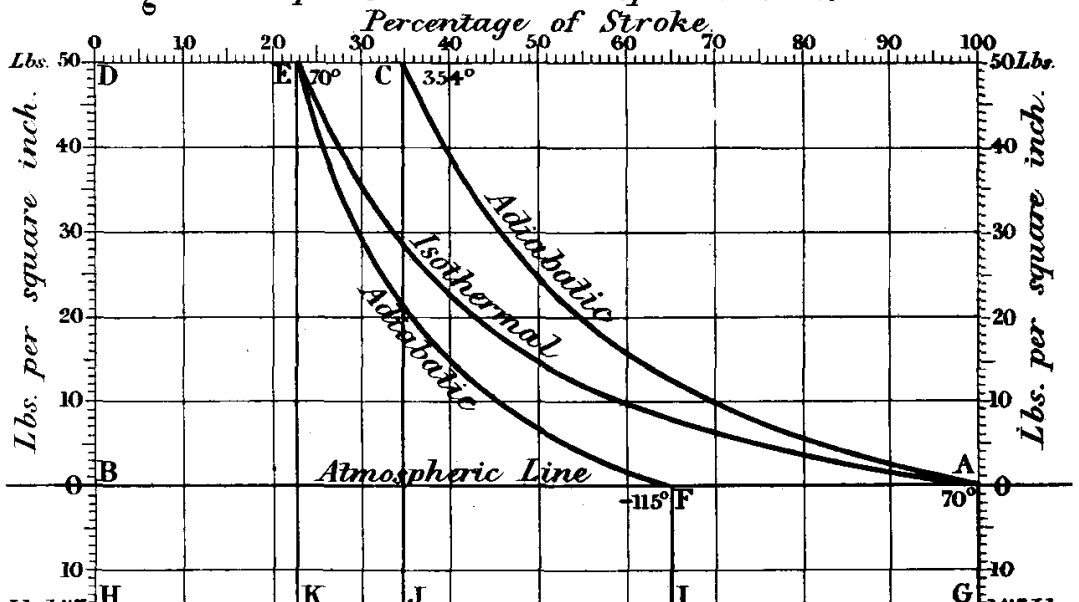

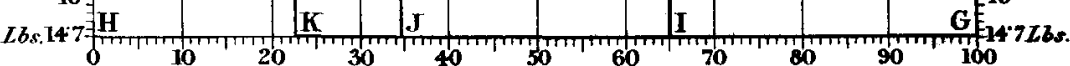

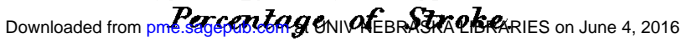

(Proceedings Inst. M.E. 1886.) 
REFRIGERATING MACHINERY. Plate 53.

Fig: 4 .

Compression Machine 1834.

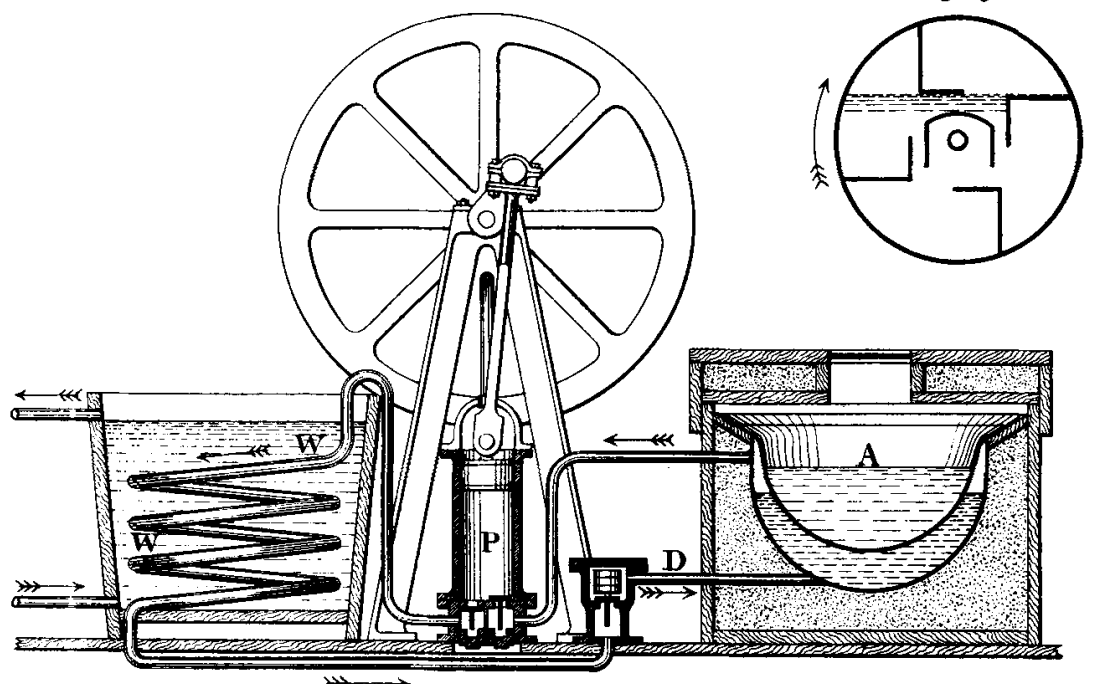

Fig. 3. Revolving Cylinder.

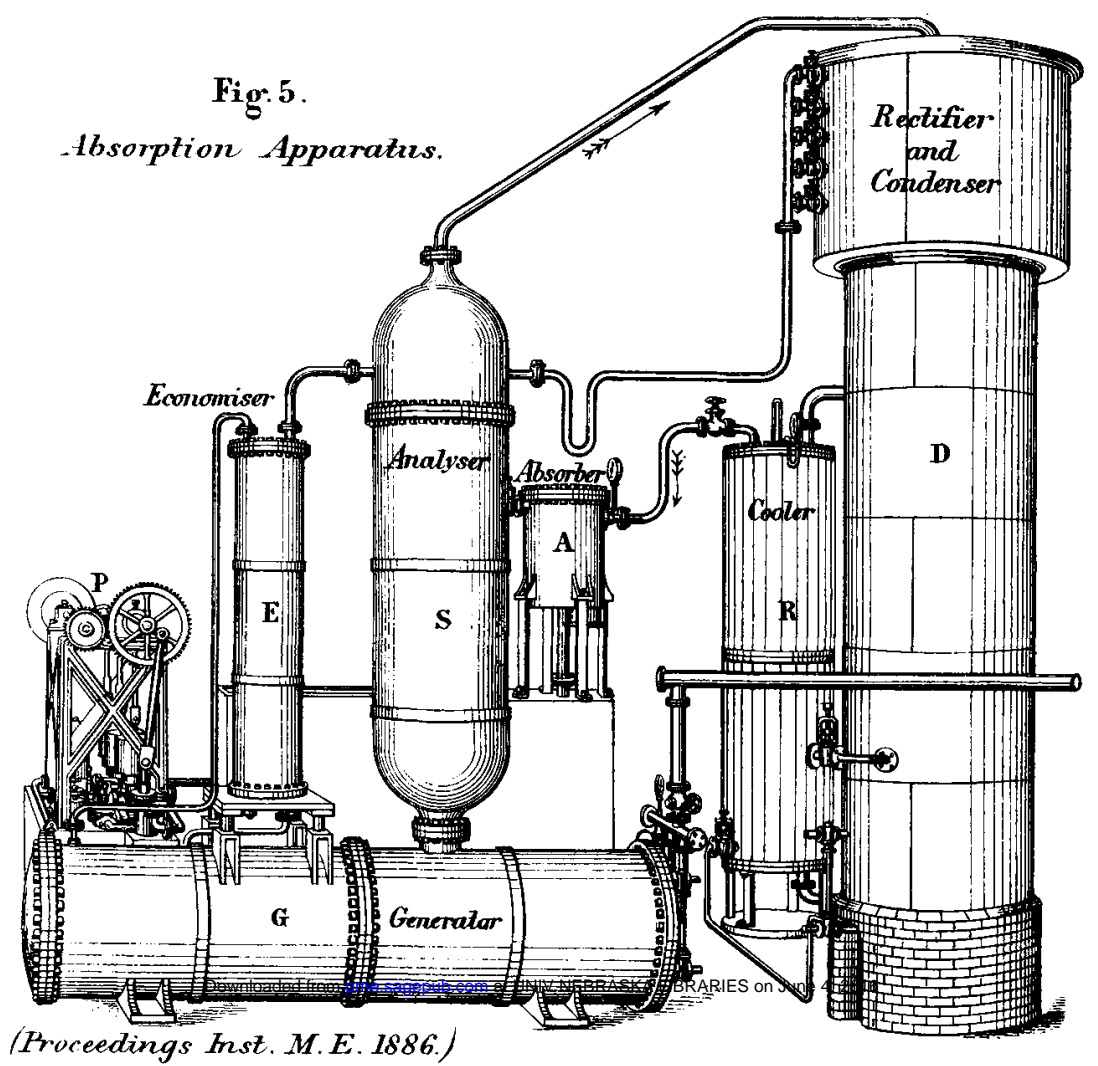



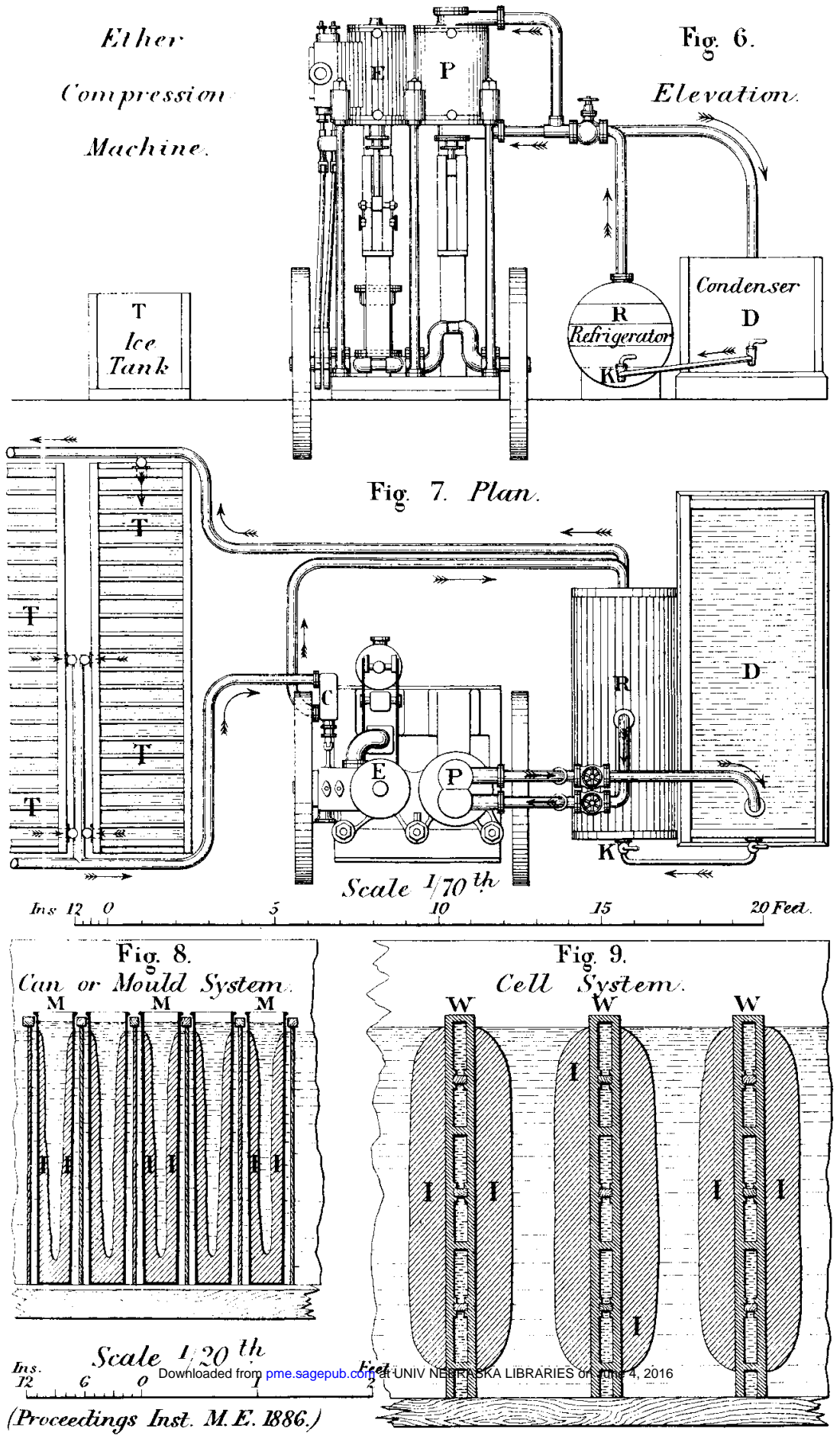

Ins. Scale 1, 20 the 
REFRIGERATING MACHINERY.

Plate 5.5.

Ammonia Compression Machine.

Fig. 10. Elevation

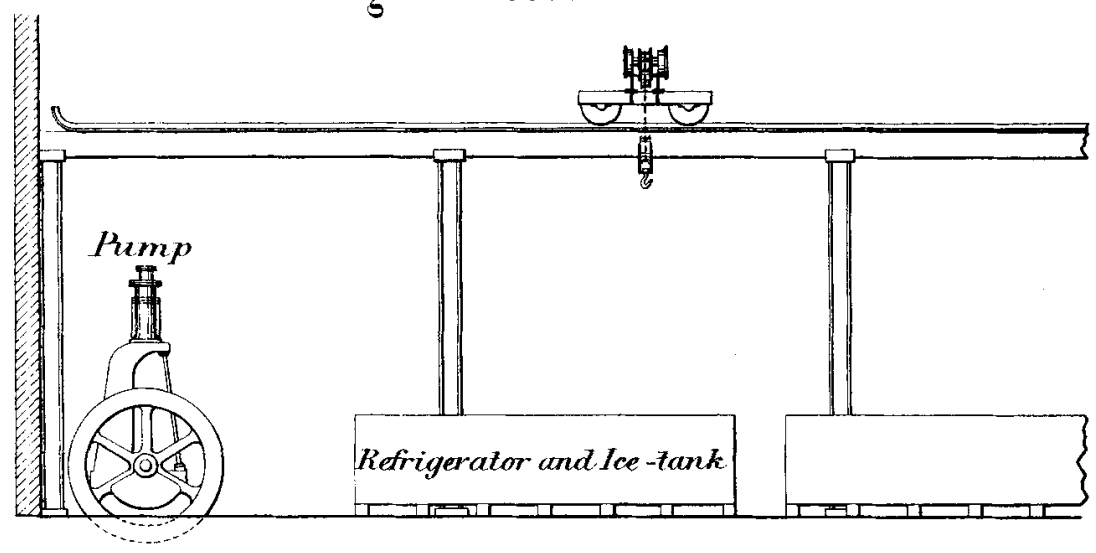

Fig. 11

Plan.

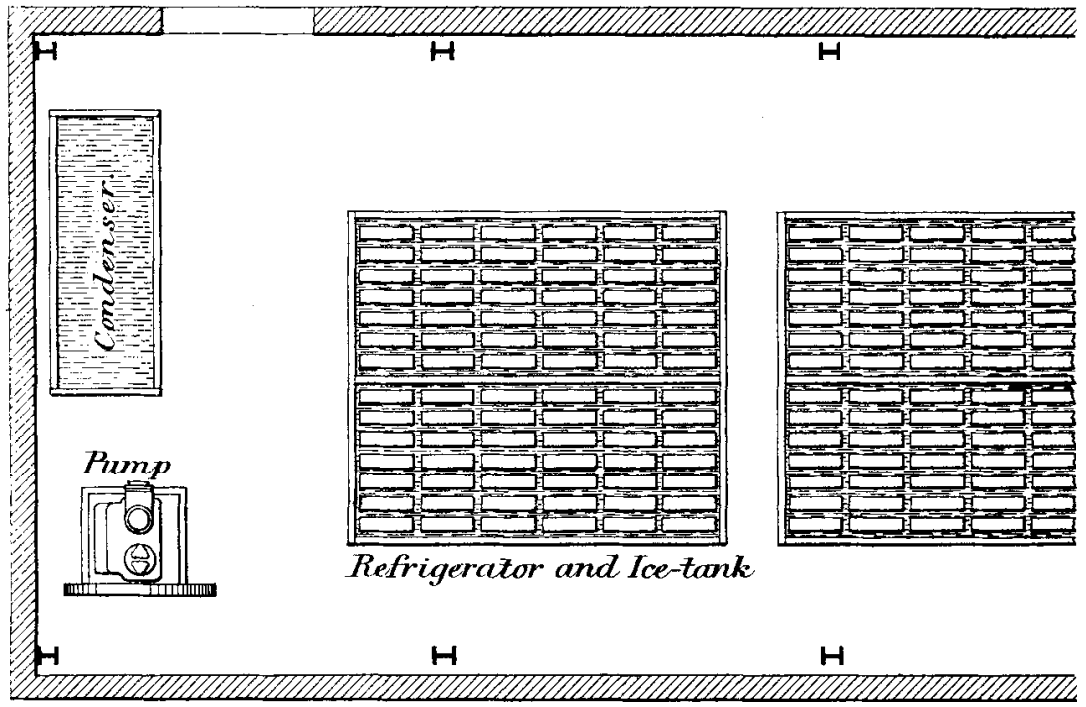

Scale $7 / 120^{\text {th }}$

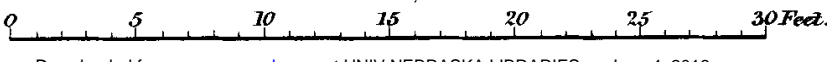

Downloaded from pme.sagepub.com at UNIV NEBRASKA LIBRARIES on June 4, 2016

(Proceedings Inst. M.E. 1886.) 
REFRIGERATING MACHINERY.

Plate 56.

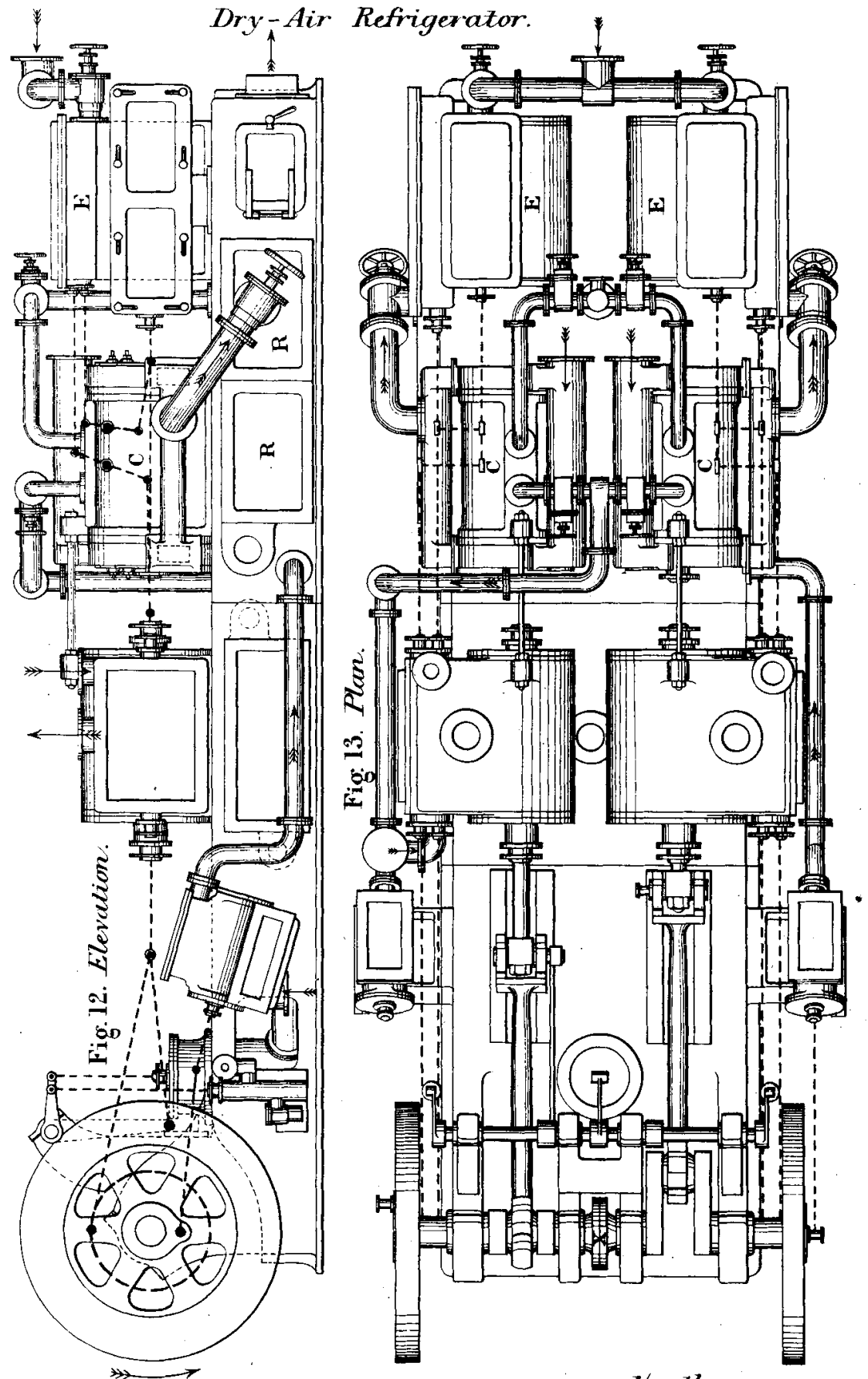

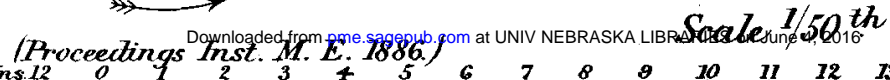

ThS 12 o 
REFRIGERATING MACHINERY. Plate 57.

Double-acting horizontal cold-Air Machine

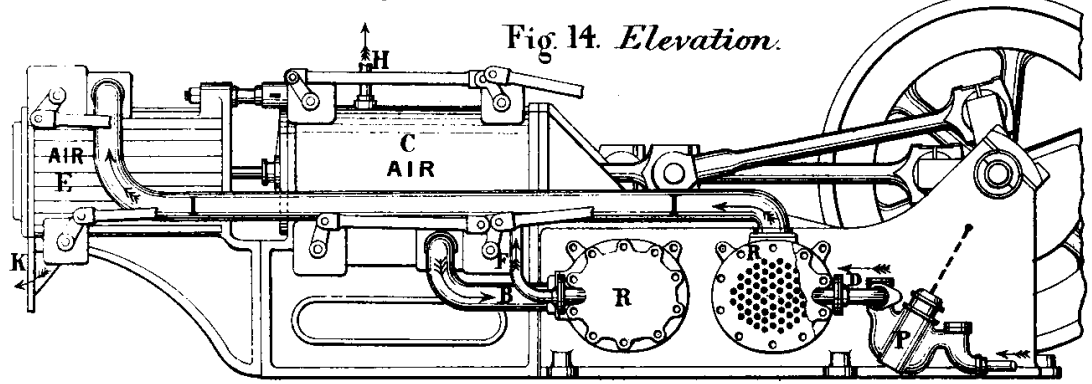

Fig: 15. Plan.

Scale $1 / 40^{\text {th }}$

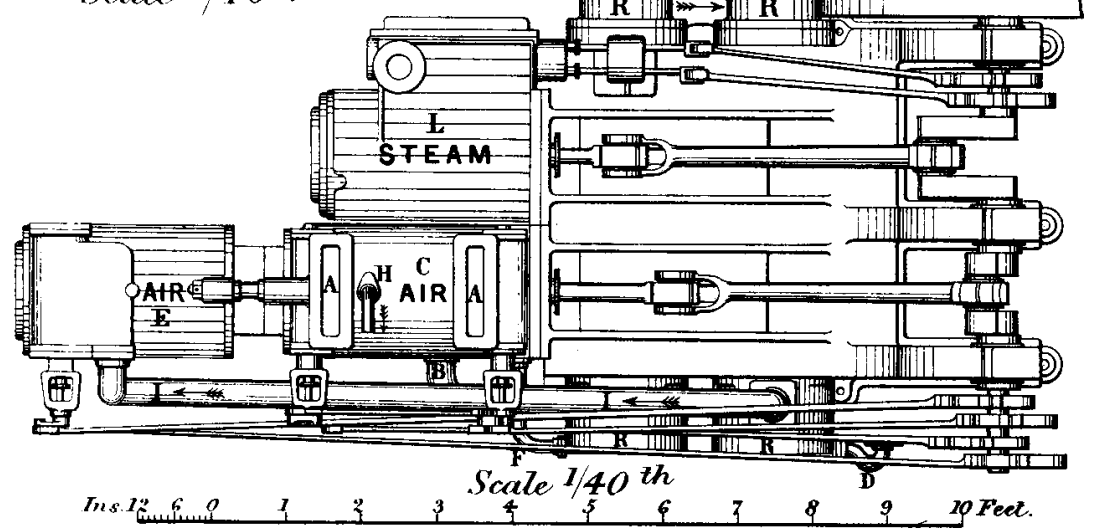

$\underset{R \rightarrow n}{\longrightarrow} \rightarrow$

Fig. 16. Section through Air Cytinders.

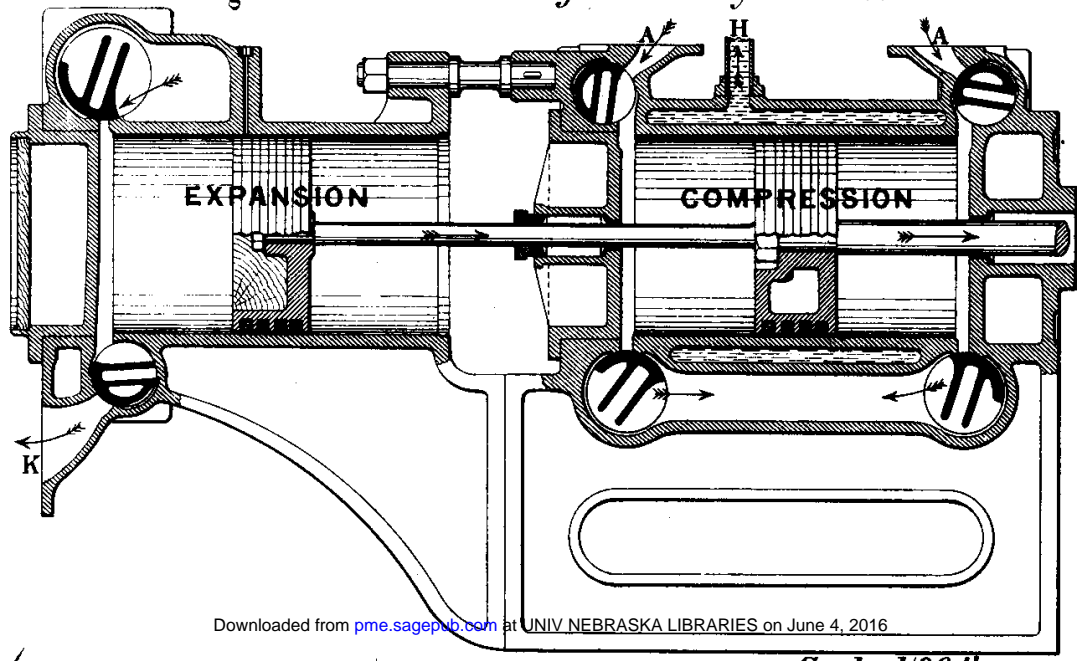


Double-acting horizontal Cold-Air Machine,

driven $b y$ compound condensing steam-engine.

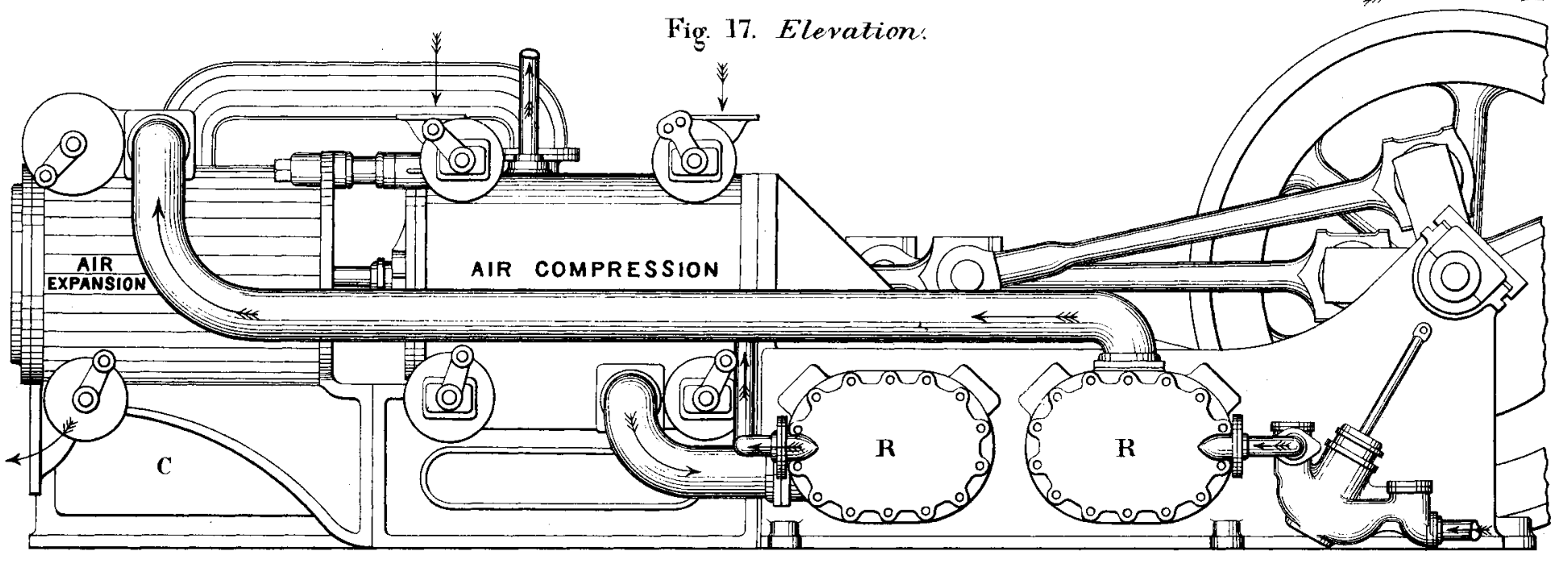

(Proceedings Inst. M. E. 1886.)

Scale $1 / 30^{\text {th }}$

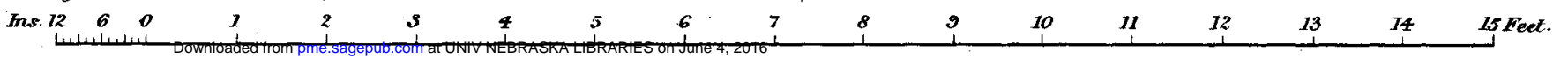




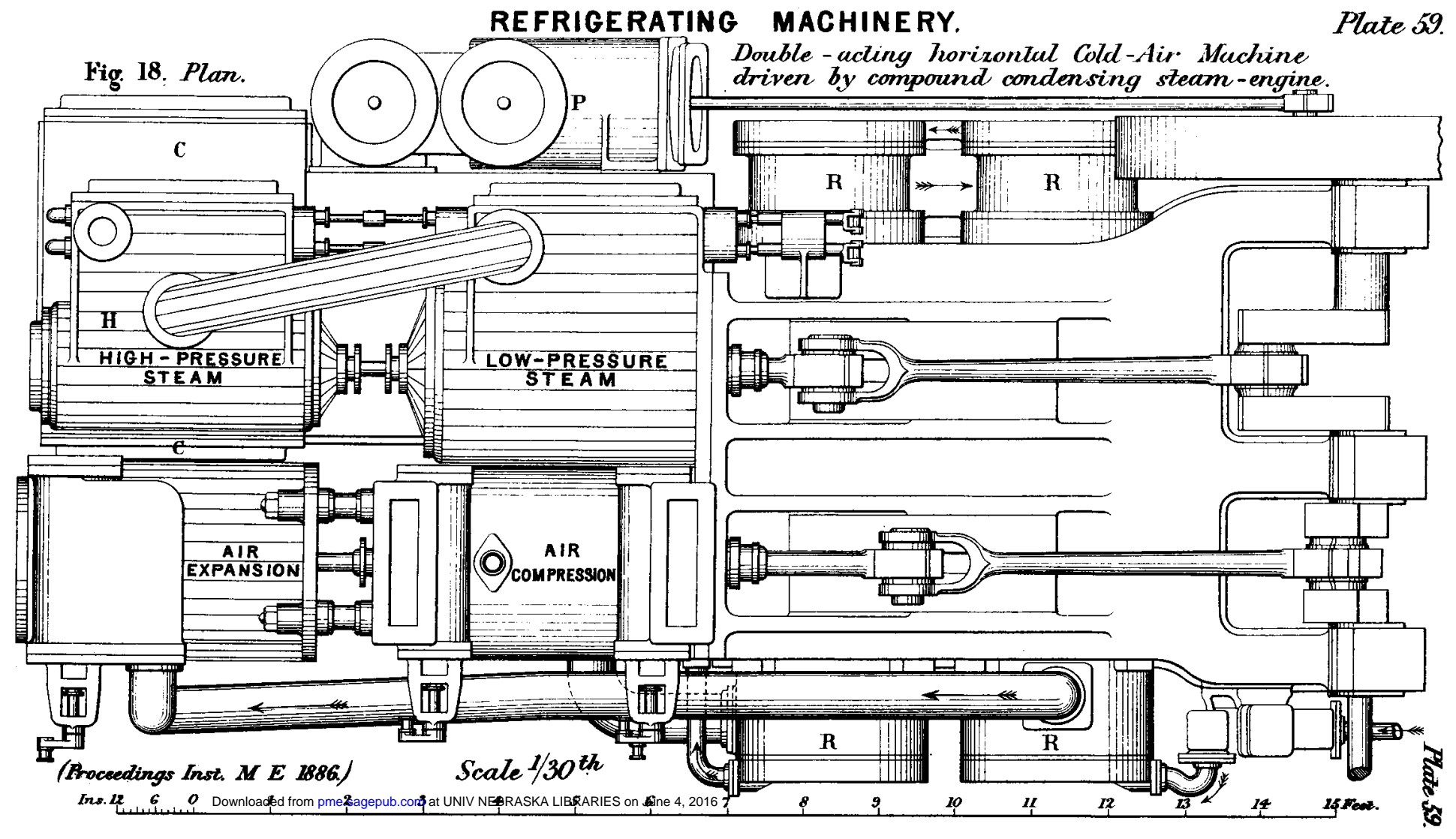


Single-acting horizontal Cold-Air Machine Fig. 19. Elevation

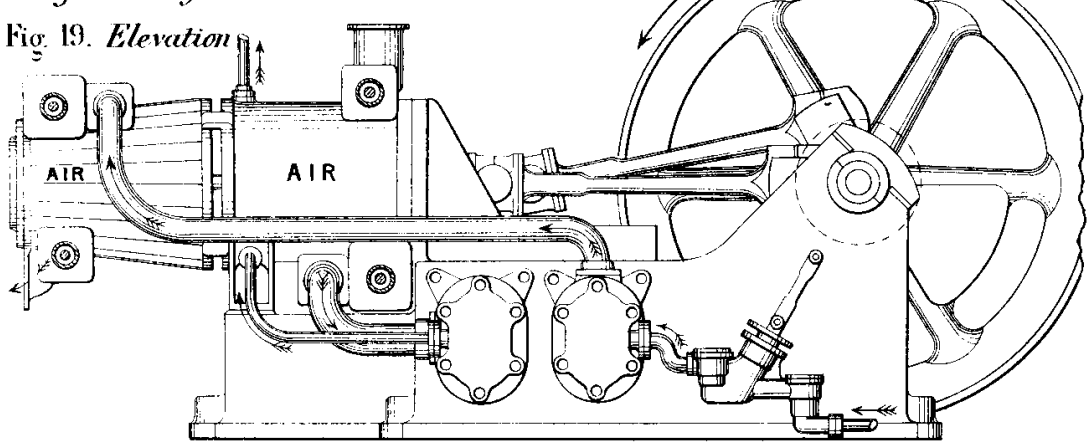

Scale $130^{\text {th }}$

Fig: 20. Plan

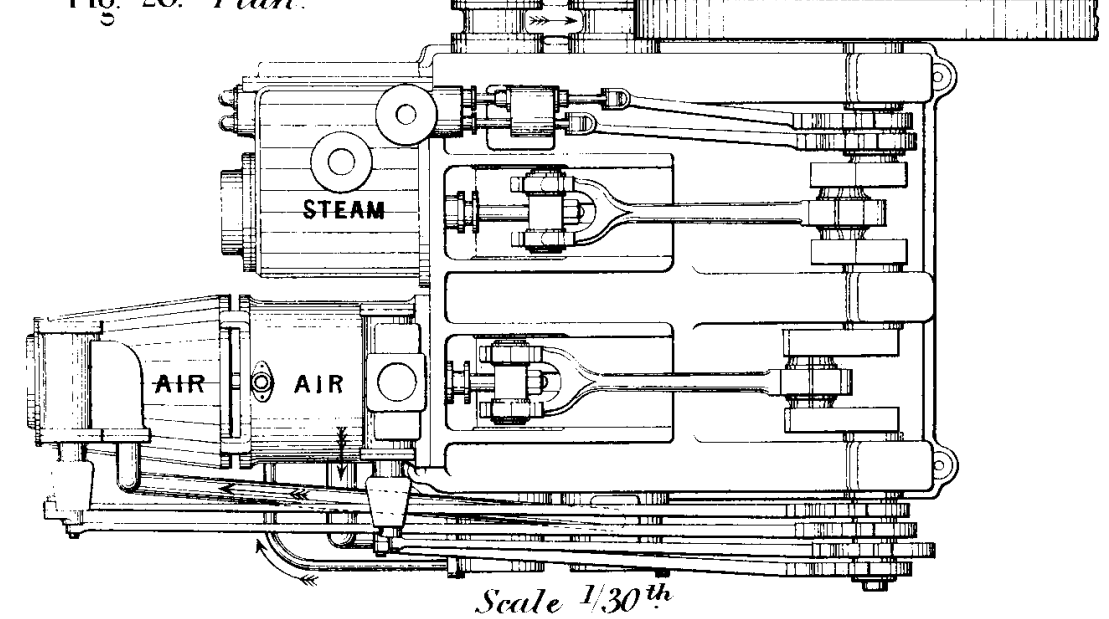

lows. 1 ?

BFeet.

Fig. 2l. Section through Air-Cylinders.

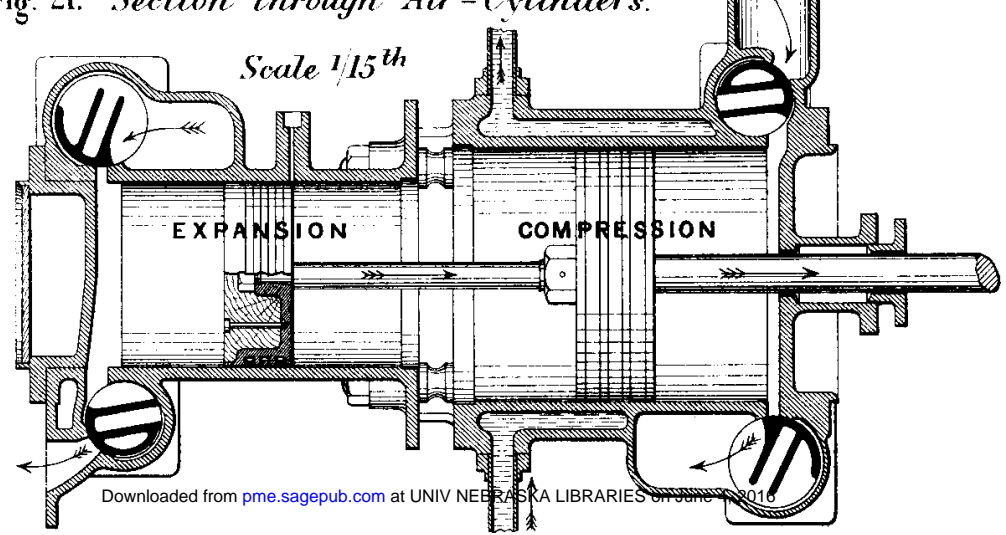

(Proceectings Inst. M. E. 1886.) 
REFRIGERATING MACHINERY. Plate 67.
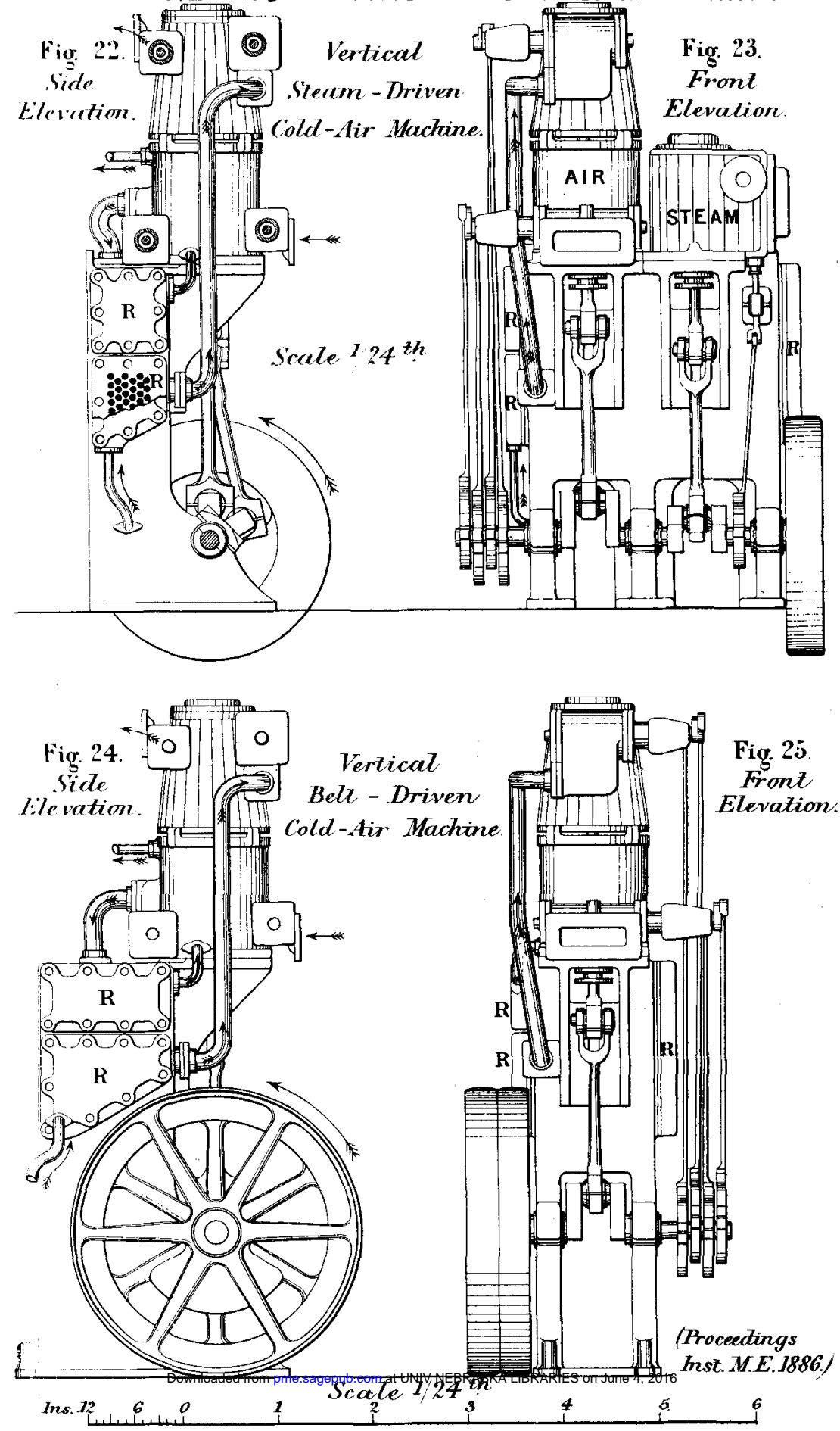


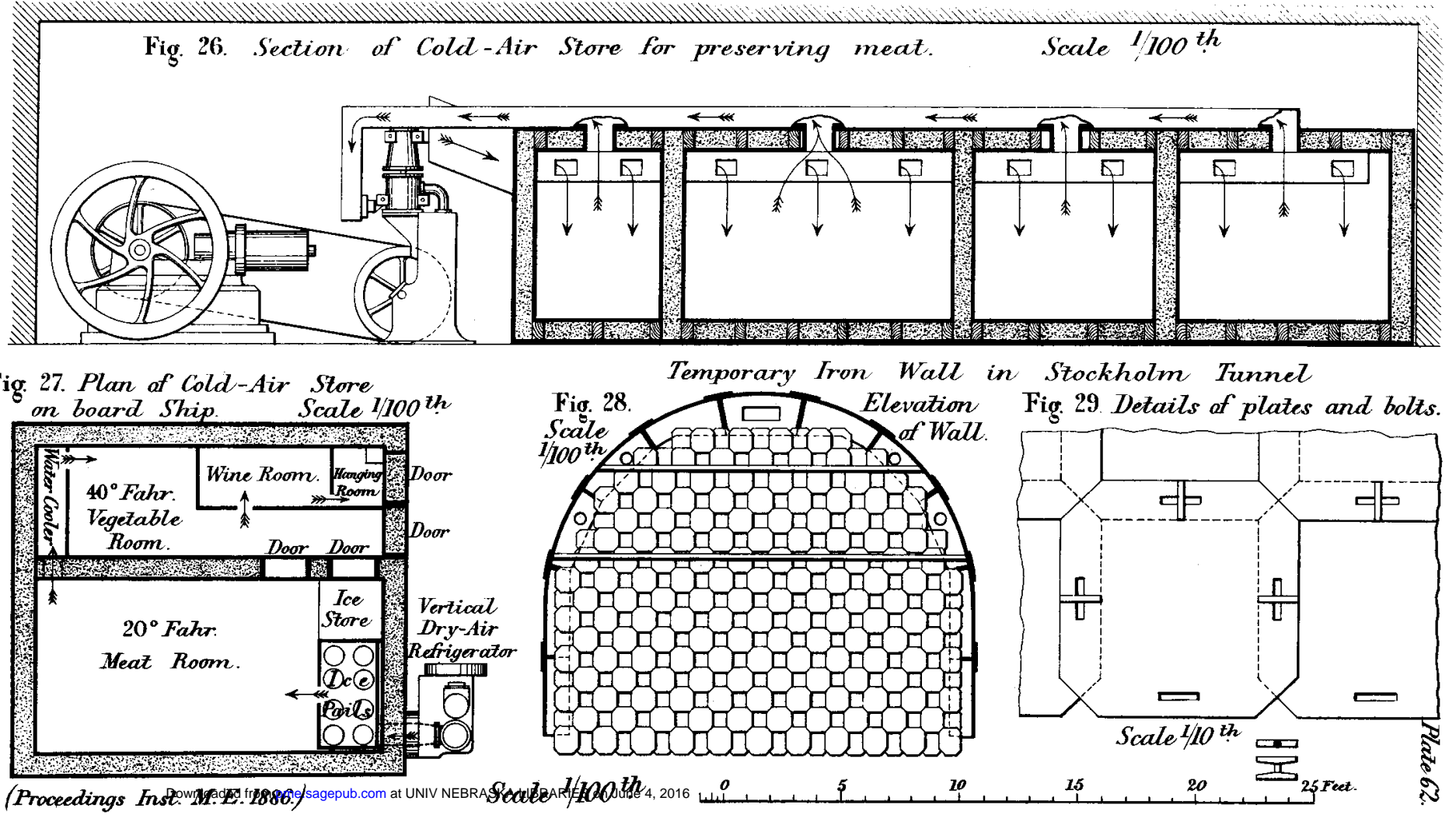


Fig. 30. Lomgitudinal Section of Stochteolm Tunnel

穷.

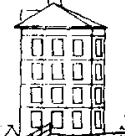

\begin{tabular}{|l|l|l|l|}
\hline 0 & 0 \\
\hline 0 & 0 & 0 & 0 \\
\hline
\end{tabular}

\section{Scale $1500^{\text {the }}$}

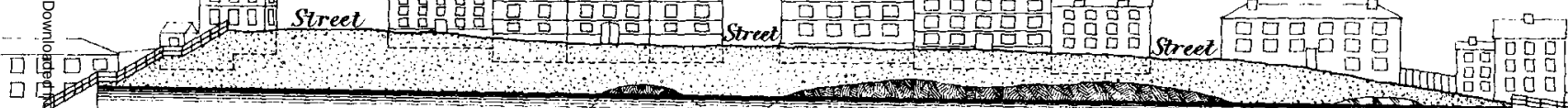

1 ㄴ. 100 zoo 300 400 500 600 700 sgoficet

Fig. 31. Cross Section.

\section{Freezing Chamber in Funnel}

Fig. 32, Longitudinal Section:

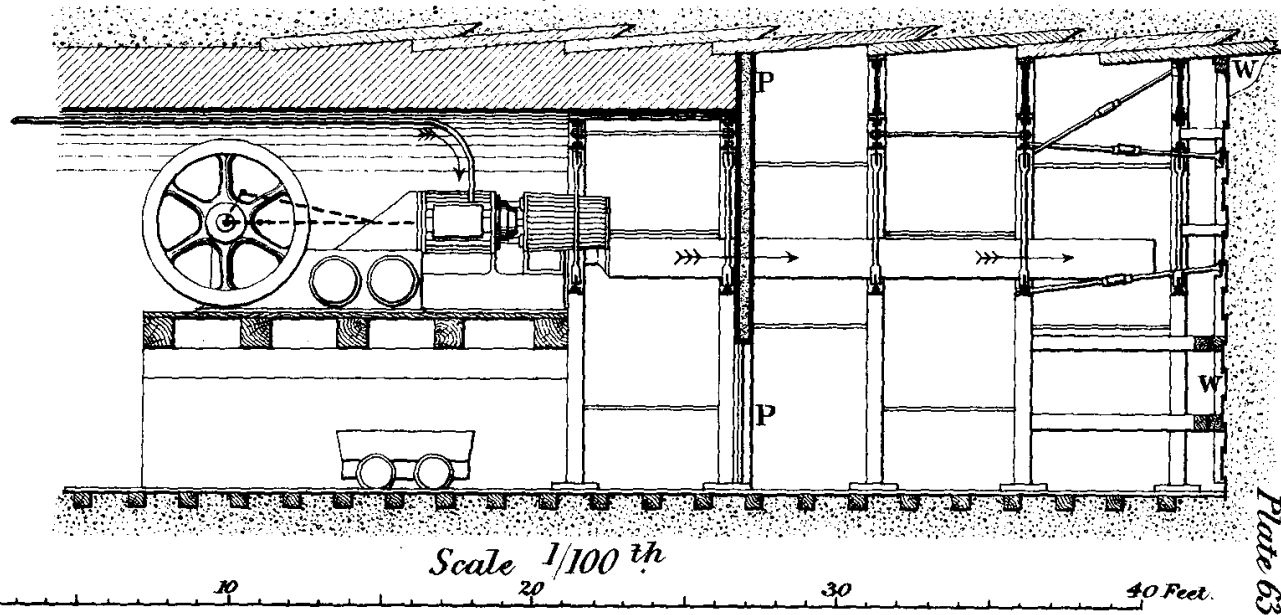

